\title{
Older but not wider. Impacts of molt frequency variation on age and growth dynamics of Newfoundland \& Labrador snow crab (Chionoecetes opilio) toward corroborating gastric mill 2 age estimations
}

Darrell Mullowney ( $\nabla$ darrell.mullowney@dfo-mpo.gc.ca )

Fisheries and Oceans Canada

Nicole O'Connell

University of New Brunswick

Rémy Rochette

University of New Brunswick

Raouf Kilada

University of New Brunswick

\section{Research Article}

Keywords: snow crab, Newfoundland \& Labrador, age band, skip molt, terminal molt, gastric mill

Posted Date: November 10th, 2021

DOI: https://doi.org/10.21203/rs.3.rs-1044348/v1

License: (9) This work is licensed under a Creative Commons Attribution 4.0 International License.

Read Full License 
Older but not wider. Impacts of molt frequency variation on age and growth dynamics of Newfoundland \& Labrador snow crab (Chionoecetes opilio) toward corroborating gastric mill age estimations

Aging specimen and survey data from a heterogeneous stock range are combined to investigate effects of molt frequency variation on age and growth dynamics and efficacy of gastric mill age band estimations in snow crab. A central assumption that bands form independent of molting is examined through analyses of molt frequency variation with an overall result of support for the hypothesis that gastric mill bands form independent of molting. This is based on an applied review approach, demonstrating blind age estimation results within and across population units featuring different rates of molt frequency interruptions in context of literature-based expected outcomes of age and growth dynamics. The comprehensive analyses overall supports the ability of gastric mill bands to track chronological ages, but non-fully explained outcomes of growth delays into sexual maturity stages in males and potential estimation error in 1-3 year old crab preclude a conclusion that absolute ages are consistently tracked throughout ontogeny. The results suggest gastric mill bands continue to form during both skip-molts and after terminal molt. Despite uncertainties, the research highlights that males originating from populations where skip-molting is prominent are older reaching fishery size than previously thought (9-10 years), with tentative average estimates of 10-12 years. The study presents novel observations of size-at-age and age-at-maturity in Newfoundland \& Labrador (NL) snow crab and broadens life history knowledge for the species. Along with corroborating gastric mill age band estimations, the study reveals future research streams to further help advance the discipline of aging crustaceans [247]. 


\subsection{Age Determination}

The demonstration by Kilada et al. (2012) of the potential ability to directly age crustaceans by counting bands in cuticular structures is arguably one of the most important developments to benefit assessment of crustacean resources in recent decades. Age-structured population models based on counting band signatures within various hard structures of animals are commonly used in assessments of fish species (i.e., Campana, 2001). Age-based models normally allow greater precision for tracking and projecting cohortspecific demographics within populations than size frequency or surplus production models commonly used in assessments of crustaceans (i.e., Hartnoll, 2001; Vogt, 2012). However, to-date, application of age band

The reliability of band counts in the gastric mill ("stomach teeth") or other parts of crustaceans to assess age has been highly debated. There is both support (i.e., Kilada et al., 2015; Huntsberger et al., 2020) and rejection (i.e., Sheriden et al., 2016; Sheriden and O'Connor, 2018; Becker et al., 2018) of the crustacean aging methods. More in-situ studies corroborating the methods are needed if aging crustaceans for stock assessment or other purposes is to become more common (Leland et al., 2011; Kilada and Driscoll, 2017; Kilada et al., 2017). Two focal topics of debate are whether or not gastric mills are retained or lost (and subsequently regenerated) during molting, and what underlying mechanisms ultimately control formation of the cuticular bands. Poor understanding of these issues are arguably the main impediments to wider adoption of the aging methods. At least two studies have suggested that a "memory-like mechanism" may control band formation, even when gastric mills are expelled and regenerated upon molting (Leland et al., 2015; Mouser et al., 2020).

64 In many crustaceans, molting schedules are temporally inconsistent over ontogeny, thus for band count techniques to track absolute ages a key assumption is that cuticular band formation (whatever the controlling mechanism(s)) occurs independent of molting (Kilada et al., 2012). In this regard, studies on populations with variability in molt frequency (herein referring to number of molts per year) or variation in ages or sizes where growth rates slow or stop constitute a useful approach to attempt corroborations of blind age estimations. Comparative studies on wild populations (herein population refers to a smaller demographic unit than stock) occupying heterogeneous environments known to affect molt frequency or growth rates, as has been done in some species of lobster (Gnanalingam et al., 2018; Huntsberger et al. 2020), would be particularly useful. 
74 This study focuses on age estimations from band counts in ossicles of the gastric mill ("stomach teeth"),

75 which were identified by Kilada et al. (2012) as a structure in which cuticular bands consistently formed.

76 Importantly, Rebert et al. (2020) recently suggested that gastric mill bands stop accruing after terminal

77 (final) molt in snow crab and hence could not be reliably used to determine age thereafter.

\subsection{Objectives \& Expected Outcomes}

81 This study primarily addresses the ability of gastric mill band counts to detect differences in molt frequency rates in populations of snow crab inhabiting heterogeneous regions of the NL shelf, and in relation to a neighbouring population of males in the northern Gulf of St. Lawrence (nGSL) (Figure 1).
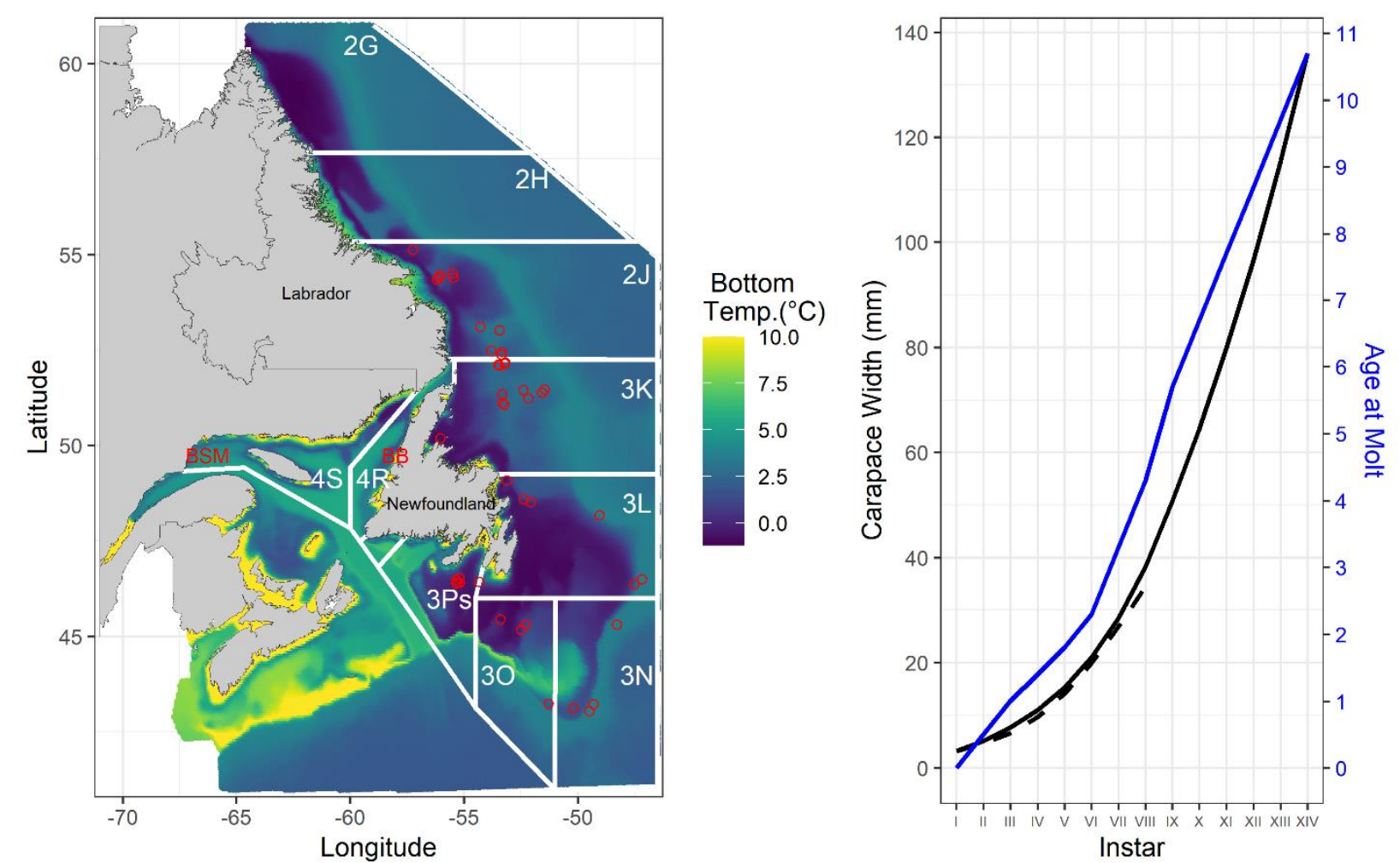

Figure 1. Left Panel. Map of locations (red points) from which crab specimens used for aging study were taken during 2015 surveys. Underlay is the mean daily bottom temperature data for September 2015 (closely aligned with age-specimen collection period across all SDs), extrapolated from the Bedford Institute of Oceanography North Atlantic Model (Wang et al., 2018). Temperatures $>10^{\circ} \mathrm{C}$ are plotted as $10^{\circ} \mathrm{C}$. White lines and associated alpha-numeric codes denote Northwest Atlantic Fisheries Organization Divisions referenced in the text. BSM and BB (red text) denote Baie Sainte-Marguerite and Bonne Bay, respectively. Right Panel. Carapace width (black lines) and estimated ages (blue line) for instars in immature and adolescent males from the northern Gulf of St. Lawrence. Dashed black lines shows measured carapace width estimations and solid black lines shows modeled carapace width estimations. Data taken from Table 1 in Sainte-Marie et al. (1995). Vertical grey lines above instar labels show estimated modal centres. 
97 The "applied review" approach associates outcomes from a dedicated aging study with field data

98 observations to examine the key research question of whether or not cuticular band deposition occurs

99 independent of molting (Note an overview of snow crab growth dynamics is forthcoming (Section 1.3), with

100 potentially unfamiliar life history terminology and concepts contained in this section more thoroughly

101 described).

102

103 Growth in crustaceans is ultimately affected by two central processes of molt frequency and molt increment.

104 This analysis predominately focuses on the process of molt frequency. Males are the sex of most analytical

105 focus. This reflects more contrast in age and growth dynamics in males than females, which is associated

106 with a higher degree of environmental regulation of age and growth processes after early ontogeny (i.e.

107 Dawe et al., 2012; Sainte-Marie et al., 2021). Of particular relevance for examinations of males is that

108 differences in temperature and population densities among portions of the NL marine shelf are $a$ priori

109 known to affect molt frequency after early post-settlement via differences in rates of skip-molting and stages

110 of terminal molt (i.e. Baker et al., 2021, Mullowney et al. 2021). Further relevant information to understand

111 examinations of males is that the comparative "control population" from the nGSL is known to have

112 minimal levels of skip-molting (Dr. Bernard Sainte-Marie, personal communication), thus growth are

113 expected to be lesser than in the NL populations.

115 We formulated seven expected outcomes relevant to both sexes and various life stages based on the known

116 literature on age and growth dynamics in snow crab as a basis to examine the reliability of gastric mill age 117 estimations:

118 1) males in NL populations with highest skip-molting rates should have lower size-at-age than those 119 from populations where skip-molting is less common;

120 2) adolescent males from all NL populations should have lower size-at-age than nGSL males due to 121 a priori anticipated greater incidences of skip-molting in NL than in nGSL;

122 3) no across-sex differences in size-at-age should occur in small crab $(\leq 40 \mathrm{~mm} C W)$ within any given 123 population as no skip-molting or maturity rate differences are expected; however, males should 124 show higher size-at-age than females thereafter $(>40 \mathrm{~mm} \mathrm{CW})$, as female terminal molt becomes 125 more abruptly commonplace near this size;

126 4) Minimal molt frequency differences after early ontogeny in females should promote similar size127 at-age across female populations but unobserved processes of greater levels of skip-molting during 128 early post-settlement stages and smaller molt increments could lead to smaller size-at-age in 129 females from cold water populations; 
5) age-at-maturity is likely to be highest in male populations where skip-molting is most common due to expected consistency in minima on instar stages where terminal molt will first occur;

6) age-at-maturity should be higher in males than females due to expected earlier commitment to terminal molt in females;

7) ages should be higher in mature versus immature animals of a same size and sex if gastric mill bands continue to accumulate after terminal molt. Females and small males should most clearly show this as they are unfished.

\subsection{Snow Crab Growth Dynamics}

\subsubsection{Age \& Maturity}

Snow crab is a stenothermic cold water decapod. It is a sexually dimorphic species with males normally growing larger than females. As in all crustaceans, growth occurs by molting. Irregular molting dynamics are linked to physiological changes and differential habitat use throughout ontogeny (Sainte-Marie and Hazel, 1992; Ernst et al., 2005; Parada et al., 2010; Kolts et al., 2015; Nichol and Somerton, 2015; Mullowney et al., 2018). Of particular relevance is the terminal molt, which stops growth (Conan and Comeau, 1986). Terminal molt occurs over a broad size range, particularly in males, in all global stocks. In Newfoundland and Labrador (NL) snow crab, terminal sizes range from about 40-150mm and 30-95mm carapace width (CW) in males and females, respectively (Mullowney et al., 2018).

Adult crab of both sexes are terminally-molted and exhibit features of being both sexually and morphometrically mature. Only sub-adult crab can molt. There are three possible "molt type outcomes" during any given molting period. A "regular-molt" entails a crab remaining morphometrically immature (sub-adult) after molting, a "skip-molt" entails a crab not molting at a time it might be expected to do so, and the aforementioned "terminal-molt" involves a crab developing morphometric features defining it as an adult upon its final molt (Conan and Comeau, 1986). Shell condition represents a subjective proxy for time elapsed since molt, and shells advanced beyond a new-shell stage (intermediate and old shell) are used to identify skip-molters (for sub-adult males) or adults that did not recently molt. Notwithstanding subjectively in visual shell condition staging (Fonseca et al., 2008), an "intermediate-shell" crab is assumed to have last molted more than one year ago and "old-shell" crab are assumed to have last molted two or more years ago.

The sexual maturation process differs across sexes (Sainte-Marie et al., 1995). The pubescent molt (into sexual maturity) in females coincides with the terminal molt, thus females become both sexually and 
morphometrically mature at the same time (i.e. a "puberty/maturity" molt). Males, however, become

165 sexually mature prior to the terminal molt (i.e. a "puberty/regular" molt). Herein, sub-adult females are

166 termed immature and sub-adult males are termed either immature (pre-pubescent [not sexually mature]) or

167 adolescent (pubescent [sexually mature]). Size-at-maturity and age-at-maturity both refer to the terminal

168 molt stage to define maturity.

170 Instar refers to the number of molts undertaken and is not equivalent to chronological years. This reflects

171 differing inter-molt periods between instar stages. In males, the puberty molt most commonly occurs at 172 instar VIII or IX (Kon and Honma, 1978; Sainte-Marie et al., 1995) and terminal molt at instars X-XIII 173 (Comeau et al., 1998; Sainte-Marie et al., 2020). In females, the puberty/maturity molt tightly conforms to 174 instars IX-X or IX-XI across both Atlantic (IX-X, Alunno-Bruscia and Sainte-Marie, 1998) and Pacific 175 (IX-XI, Orensanz et al., 2007) Ocean stocks. Accordingly, the instar and size ranges over which snow crab 176 terminally molt are higher and overall more variable in males than females.

In most global snow crab stocks sexual size dimorphism promotes male-only fisheries targeting largest males. Present best estimates of ages at which males in the Atlantic Canadian stock, which encompasses all of NL and more broadly all portions of Atlantic Canada (Puebla et al., 2008), reach legal fishery size of 95mm CW after first settling to the bottom is 9-10 years (i.e., Sainte-Marie et al., 1995; Comeau et al., 1998). The most consistent long-term studies tracking cohorts in the wild come from the northern Gulf of

183 St. Lawrence (nGSL), in Atlantic Canada (NAFO 4S [BSM], Figure 1). A comprehensive and progressive 184 monitoring program featuring frequent field sampling of localized populations in the nSGSL, coupled with 185 a suite of complementary lab-based growth studies, has produced relatively refined size-at-age, size-at186 instar, and age-at-instar estimates (i.e., Sainte-Marie et al. 1995; 1996; Lovrich et al., 1995; Alunno-Bruscia 187 and Sainte-Marie, 1998; Sainte-Marie et al., 2020). Maximum longevity of males following terminal molt 188 has been estimated at about 7-8 years based on shell deterioration and dactyl ('toe nail') wear (Fonseca et 189 al., 2008). Although such longevity is not likely to occur in presence of fisheries exploitation (for males in 190 particular) and 'normal' post-terminal molt longevities of both sexes are not known, it is assumed most 191 crab would not typically reach this 7-8 year maximum estimated from males.

\subsubsection{Molt Frequency}

A synopsis of the literature indicates that variability occurs in both molt frequency and molt increment processes, but moreso in molt frequency. This assertion is based on similarity in reports of size-at-instar in both sexes both across and within global snow crab stocks, including in Bonne Bay (Comeau et al., 1998) 
and the nGSL (Sainte-Marie et al., 1995) (BB and BSM on Figure 1 map), the Eastern Bering Sea of Alaska

199 (Ernst et al., 2005; Orensanz et al., 2007), and the Seas of Japan and Okhotsk (Ito, 1970; Kon, 1980).

200 Accordingly, despite a weak positive association between temperature and molt increment (Sainte-Marie

201 et al., 2020), relative consistency in size-at-instar across populations and stocks highlights the importance

202 of molt frequency in regulating size-at-age, size-at-maturity, and age-at-maturity in different snow crab

203 populations. Ultimately, with more variability ascribed to molt frequency than molt increment, instar-at-

204 terminal molt is a dominant determinant of terminal size in most individuals. In-turn, instar-at-terminal molt

205 is a direct function of cumulative molt frequency over ontogeny.

Molt frequency progressively slows throughout life. Both sexes molt multiple times in each of the first twothree years of life. Sainte-Marie et al. (1995) estimated instars III and VI to occur at 12 and 28 months of age (age henceforth refers to post-settlement age) (Figure 1), and more recently Yamamoto et al. (2015a) and Sainte-Marie et al. (2020) reported inter-molt periods for crab reared in tanks to remain less than a year up to at least instar VII under most rearing conditions.

Following a frequent but progressively slowing molt rate in earliest post-settlement ontogeny, a near-annual molting schedule often becomes established over the instar VI (Sainte-Marie et al., 1995; Comeau et al., 1998) to instar VIII (Yamamoto et al., 2015b) range, depending on environmental conditions. Thereafter, skip-molting of annual molts by males becomes commonplace in some populations, particularly in moderately-large adolescent males (Taylor et al., 1994; Hébert et al., 2002; Dawe et al., 2012; Yamamoto et al., 2018b; Murphy, 2019, Mullowney et al., 2021). In populations where this occurs, it can lead to average molt frequency rates beyond about instars VII-VIII becoming less than annual. In wild NL populations, Mullowney and Baker (2021) recently showed skip-molting to be highest in 50-100mm CW adolescent males, with rates as high as $25-50 \%$ of individuals skip-molting in some populations in some years. These sizes roughly conform to instars IX - XII (Figure 1). Laboratory studies have shown that skipmolting also occurs during early post-settlement ontogeny, with delayed inter-molt periods potentially occurring in all early-life instars under the right (namely cold) conditions (Yamamoto et al., 1998a; SainteMarie et al., 2021). Henceforth, discussion and interpretation of ages and growth is applied only to postsettlement stages.

The size at which males terminally molt is particularly important to fisheries. Coincidental increasing probabilities of skip-molting (near-exclusive to males) and terminally molting (applicable to both sexes) with individual size after mid-life stages (instars) are reached slows molt frequency over ontogeny. For example, to focus on a relatively small $\mathrm{CW}$ range of $20 \mathrm{~mm}$ centered near legal-size of $95 \mathrm{~mm} \mathrm{CW}$, 
232 Mullowney and Baker (2021) showed that over the past twenty-five years males throughout different

233 portions of the NL stock range had a $25-40 \%$ probability of being terminally-molted at $80 \mathrm{~mm} \mathrm{CW}$ versus

234 a 50-75\% probability of being terminally-molted at $100 \mathrm{~mm} \mathrm{CW}$. These sizes most closely conform to

235 instars XI and XII (Figure 1) and demonstrate the pronounced fisheries yield losses that can be associated

236 with losses to terminal molt at small sizes.

Molt increment has been shown to vary within and across wild snow crab populations throughout Atlantic Canada, as well as in numerous tank-based studies. However, to generalize, the variability in reported growth increments at molt is relatively small, with males ranging from about 50-110mm CW consistently growing 12-20mm CW upon molting (Miller and Watson, 1976; Moriyasu et al., 1987; Robichaud et al., 1989; Taylor and Hoening, 1990; Hoening et al., 1994; Sainte-Marie et al., 1995; Comeau et al., 1998). Growth patterns follow a near-linear process that reflects overall decreasing relative but increasing absolute growth increments from one instar to the next. Sainte-Marie et al. (1995) estimated percentage growth increments to decrease from $60.5 \%$ to $34.3 \%$ from instars I-VII, and from $32.6 \%$ to $17.9 \%$ from instars VIII-XIV. The rich literature on growth increments in snow crab conforms well with the tabulated instar size ranges and modal centres presented in (Ito, 1970) and Sainte-Marie et al. (1995) in the Sea of Japan and the nGSL respectively, with the latter used herein for quantitative comparisons (Figure 1).

The phenomenon of similar size-at-instar across and within both Atlantic and Pacific stocks holds particularly well at smallest sizes (Yamamoto et al., 1998a; Sainte-Marie et al., 2021). Although variability of sizes around instar modal centres increases after smallest size stages, particularly under different environmental conditions (Sainte-Marie et al., 2021), modal sizes in crab remain similar up to about instar VIII at $\sim 40 \mathrm{~mm} \mathrm{CW}$. Notwithstanding individual variation in molt increment, a typical male would be expected to need to undergo another four to five molts after instar VIII to achieve legal-size (95mm CW) at instar XII or XIII (i.e., Ito, 1970; Sainte-Marie et al., 1995).

Size-at-instar is similar across sexes during early ontogeny but diverges in mid-life stages, with the divergence particularly obvious upon sexual maturation in females. A historic field-based report showed tight across-sex coupling in size-at-instar occurred at all comparative instars (Ito, 1970), but recent labbased studies have shown tight correspondence of male and female sizes only holds until instar VIII

264 (Yamamoto et al., 2015b; Sainte-Marie et al., 2020). Following instar VIII, a divergence in size-at-instar 265 over instars IX-XI (reported as ages 5.7 to 7.7 years in Sainte-Marie et al., (1995)) occurs, whereby females 
tend to be smaller than males (Sainte-Marie et al., 2021). This across-sex size divergence at stages associated with the female puberty/terminal molt likely reflects divergent energy allocation as females begin to invest more energy into reproduction (Alunno-Bruscia and Sainte-Marie, 1998; Dawe et al., 2012).

\subsubsection{Factors Affecting Molting}

Differences in molt frequency, molt increment, and terminal size can be directly or indirectly affected by abiotic factors including pre-molt size, temperature, and population density. Beyond systematically prolonged molt frequency periods over early instars (up to instar VIII) (Yamamoto et al. 1998a; SainteMarie et al., 2021), as previously detailed (Section 1.3.2), larger pre-molt sizes (associated with higher instar stages) are associated with increased probabilities of terminal molt in individuals of both sexes as well as increased skip-molting probabilities in adolescent males.

For temperature, the overall directional effects on growth dynamics are well understood. Effectively, cold conditions slow molt frequency and prolong inter-molt periods either progressively (earliest post-settlement instars in both sexes), intermittently (annual skip-molting in adolescent males), or permanently (terminalmolting in both sexes) at all life stages. Other factors being equal, snow crab follow a reverse temperaturesize rule for ectotherms (Sainte-Marie et al., 2020), with those occupying cold areas often smaller in-general than those in warm areas (Burmeister and Sainte-Marie, 2010). The suppression of molt frequency by cold conditions is ultimately more complex in males due to the higher levels of skip-molting once near-annual molting schedule stages are reached and the greater range of potential instars over which terminal molt occurs.

The effects of population density on molt frequency and terminal size have not been as thoroughly studied as those of temperature, but knowledge on the importance of population density in regulating growth dynamics is increasing. Low density of largest (most competitive) males has recently been linked to small terminal molt sizes in males, theoretically related to earlier allocation of energy into reproduction over growth following relaxed intraspecific competition for access to food and space or other resources (Mullowney and Baker, 2021). Subsequently, Murphy (2021) showed a linkage of terminal molt size in males to recruitment density, with individuals in strong cohorts reaching overall larger terminal sizes than those in weak cohorts. 
from previous studies (Hébert et al., 2002; 2017). This outcome promotes overall greater sizes within populations through an overall greater number of molts occurring over ontogeny as the "stop point" for molting is prolonged. Moreover, the regulatory influences of large male density on growth are likely further intertwined with mating success in adolescent males, which in-turn plausibly affect molt-type "decisions" at any given instar upon which one of the three molt-type outcomes (regular, skip, terminal) are possible. Although adolescent males are capable of mating with females, they are inferior breeders and competitors than adult males, and in particular large adult males (Claxton et al., 1994; Sainte-Marie et al., 1997). Nonetheless, in the absence of sufficient competition from large adult males, adolescents can become increasingly successful at mating. Mating success, or lack thereof, may influence subsequent molting "decisions" in adolescent males, although there are competing hypotheses on whether mating success at adolescent stages promotes or deters from advancing the timeline of terminal molt (Elner and Beninger, 1995; Comeau et al., 1998). This area of molting dynamics requires further research but mating success in adolescent males is ultimately an avenue via which population density affects age and growth outcomes.

At-present, interactions and synergies between temperature and population density (of intermediate-large size males in particular) in regulating molt frequency and terminal sizes within populations are not well understood. However, the recent observations by Mullowney and Baker (2021) suggest density of large males could override temperature in regulating growth. For example, over the past 25 years larger size-atterminal molt has occurred in males in cold water dense populations (Divisions 3LNO, Figure 1) than in warmer water less dense populations (Divisions 2J3K, Figure 1) within the NL stock range. This observation aligns with a recent similar report from the Eastern Bering Sea, where average size-at-terminal molt has recently been larger in northern cold-water populations than in southern warmer water populations, coincident with an on-going northward distributional shift in densest cohorts of crab within that expansive stock range (Dr. Ben Daly, personal communication).

\subsection{NL Marine Ecosystem and Snow Crab Population Dynamics}

The majority of the Atlantic Canadian snow crab stock occurs in NL waters, with NL consistently being the world's largest single-source of market supplies for three decades. NL snow crab is an ideal stock upon which to examine the efficacy of direct age determination due to heterogeneous bathymetric, thermal, and population density attributes across a large stock range. In particular, this region provides a strong basis to examine the key assumption that gastric mill bands form independent of molting. This is because skipmolting rates in males differ across population units and size-at-terminal molt is known to vary considerably over the expansive stock range (Mullowney and Baker, 2021; Baker et al., 2021). 
335 The dynamic NL marine shelf encompasses several "eco-zones" within it. The northernmost limit of the 336 Atlantic Canadian snow crab stock range occurs in the Northwest Atlantic Fisheries Organization (NAFO) 337 Division $2 \mathrm{H}$, off central Labrador (Figure 1), although in recent years few crab have been found north 338 beyond the Division 2J border (Baker et al., 2021). Snow crab extending from Division 2H down through $3392 \mathrm{~J}$ and $3 \mathrm{~K}$ occupy a region where shallow/cold nearshore plateaus and offshore banks (i.e., 100-250m, 0$3402{ }^{\circ} \mathrm{C}$ ) are intersected by deep/warm channels (i.e. 400-600m, 3-4 ${ }^{\circ} \mathrm{C}$ ) (Mullowney et al., 2018; Baker et al., 341 2021). Relative to other parts of the stock range within NL waters, the extent of shallow/cold habitat is low 342 and deep/warm habitat is high in Divisions $2 \mathrm{~J}$ and $3 \mathrm{~K}$. The cold conditions in the shallows reflect the 343 presence of the Cold Intermediate Layer (CIL), a mass of $<0{ }^{\circ} \mathrm{C}$ that develops from advection of surface344 chilled water down into the water column, which persists year-round at intermediate depths (Colbourne and 345 Mertz, 1998). The shallow/cold regions are common habitats for small to mid-sized crab in the range of 346 about 25-50mm CW (Dawe and Colbourne, 2002; Mullowney et al., 2018) and are harder (typically gravel 347 and rock) than deeper substrates (typically mud) (Piper, 1991). Large male snow crab are commonly found 348 in deeper areas, which the fishery targets (Dawe and Colbourne, 2002; Mullowney et al., 2018). Fisheries 349 in this northern portion of the stock range have historically harvested the snow crab resource at higher 350 exploitation rates (fraction of the large male biomass removed by fishing) than in other divisions, and 351 overall densities of large male crab are often lower or more patchily distributed here than in other divisions 352 (Mullowney and Baker, 2020; Baker et al., 2021). Skip-molting incidence in snow crab males is usually 353 low in these overall deeper, warmer, and often low relative density areas (Mullowney and Baker, 2021).

The Grand Bank area of the NL shelf, represented by NAFO Divisions 3L, 3N, and 3O, constitutes a large 356 shallow (i.e. $<400 \mathrm{~m}$ ) and cold underwater plateau as large as the island of Newfoundland. The majority of 357 snow crab biomass in the NL portion of the stock occurs here, with approximately $75 \%$ of fishery removals 358 coming from this area over the past decade (Baker et al., 2021). Fisheries exploitation rates are normally 359 lowest here, while fisheries catch rates and associated densities of large crab are typically highest in this 360 area of the NL marine shelf (Mullowney and Baker, 2021; Baker et al., 2021). The CIL covers most of the 361 bottom, with warm water ranging from about $2-4^{\circ} \mathrm{C}$ restricted to the spatially limited slope edges 362 (Mullowney et al., 2018). The area does contain a section of unusually high bottom temperatures along the 363 southwest slope of the bank, where Gulf Stream 'slope water' intrudes. Shallow substrates of the Grand 364 Bank are comprised of a mixture of gravel, sand, and shell, while sand and mud are common on the slope 365 edges and other deep intrusions of the bank (Piper, 1991). Skip-molting incidence in snow crab males is 366 normally moderate here (Mullowney and Baker, 2021). 
Finally, with respect to areas of the snow crab stock range relevant to this study is the marine shelf ecosystem off the southern portion of the Island of Newfoundland, represented by NAFO Subdivision 3Ps. This area is spatially small and overall shallowest of all NL divisions. Relative to other divisions, this one features grounds that are both very cold and very warm. Shallow cold plateaus dominate, with even the intersecting channels rarely exceeding 200-250m depth. Snow crab are entrapped in this overall shallow and very cold habitat because temperatures warm abruptly to unsuitably high temperatures (i.e., $>4^{\circ} \mathrm{C}$ ) as depths over the slope edges increase (Mullowney et al., 2018). Virtually all crab here are captured in water below $2^{\circ} \mathrm{C}$, with most in water $<1{ }^{\circ} \mathrm{C}$ (Dawe et al., 2012; Mullowney et al., 2020). The substrate here is very hard on top of the dominant banks, but sand-mud intrudes in the intersecting channels and slope edges (Piper, 1991). This area is typically subjected to intermediate fisheries exploitation rates and features intermediate stock densities relative to the other study divisions, although it has featured both extreme highs and lows in exploitation rates and associated fisheries catch rates since 1995 (Baker et al., 2021). Skipmolting rates in males are consistently highest in this portion of the NL marine shelf (Dawe et al., 2012). Interestingly, this division also contains a population of snow crab that uniquely and frequently terminally molts at small sizes, with unusually low proportions of males reaching exploitable sizes in many years (Baker et al., 2021).

This analysis utilized Study Divisions (SDs) '2J3K', '3LNO', and '3Ps' as the basis for spatial comparisons of age and growth dynamics. This is based on habitat variation that aligns with population differences in age and growth processes. To bridge the examination of efficacy of the aging methods to contexts of the geographic partitioning of the SDs, we anticipate:

For males, given the rankings of skip-molting rates range from lowest to highest as $2 \mathrm{~J} 3 \mathrm{~K}, 3 \mathrm{LNO}$, and $3 \mathrm{Ps}$, we expect 3Ps to have lowest size-at-age and $2 \mathrm{~J} 3 \mathrm{~K}$ to have highest size-at-age. However, opposing "greater forces" of higher ambient temperatures in $2 \mathrm{~J} 3 \mathrm{~K}$ versus higher population densities of large males in 3LNO could affect how results from either SD relate to one another and deviate from 3Ps. In comparisons to adolescent males in the nGSL, the higher levels of skip-molting in NL populations should lead to lower size-at-age in all NL groups, with greatest difference in SD 3Ps and likelihood for least difference in SD 2J3K. For age-at-maturity, we expect highest age-at-maturity in SD 3Ps due to the slower growing conditions, assuming males would strive to achieve a relatively high instar stage (associated with a relatively large size) before committing to terminal molt. With the least common incidence of skip-molting occurring in $2 \mathrm{~J} 3 \mathrm{~K}$, we expect age-at-maturity to be lowest in males that SD. However, again, competing forces of temperature versus population density could affect the extent to which SD 2J3K and SD 3LNO have lower age-at-maturity than SD 3Ps, particularly in light of modest sample sizes used in this study. 
403 For females, with little to no incidence of skip-molting, we expect little difference is size-at-age across SDs.

404 Further, given conformity to a limited number of instars at terminal molt, we expect little difference in age-

405 at-maturity across SDs. However, it is possible smaller molt increments in cold conditions (not measured

406 in this study) could lead to lowest [highest] size-at-age in SDs 3Ps [2J3K] respectively. It is also possible

407 unmeasured incidence of skip-molting at early instars could affect the outcome in the same way, with

408 coldest [warmest] 3Ps [2J3K] having lowest and highest size-at-age respectively due to contrasting thermal 409 regimes.

Across sexes, there should be no differences in size-at-age in small crab where no divergence in sex-specific

412 maturity processes occur within any SD. In mid-large crab of either sex, after stages where sex-specific

413 divergences in maturity processes occur, size-at-age is expected to be higher in males in all SDs. Age-at-

414 maturity should be higher in males than females in all SDs because they normally undergo terminal molt at

415 higher instars.

417 If gastric mill bands continue to accumulate after terminal molt ages of same-sized crab across maturity 418 groups should be higher in mature versus immature crab in both sexes in all SDs.

\subsection{Surveys}

423 Snow crab were opportunistically taken for age determination from various inshore (trap) and offshore

424 (trawl) surveys conducted by the Department of Fisheries and Oceans (DFO) Canada, NL Region, in 2015.

425 The majority of samples came from offshore trawl surveys, with only a few inshore sites in NAFO Divisions

$4263 \mathrm{~K}$ and $3 \mathrm{~L}$ taking samples from trap surveys (Figure 1). In total, 321 individuals including both sexes and

427 ranging from $10-144 \mathrm{~mm} \mathrm{CW}$ were included in the aging study. For presentation, survey locations were

428 plotted against bottom temperature data for September 2015, with estimates of mean monthly temperature

429 data extracted from the Bedford Institute of Oceanography North Atlantic Model (BNAM) of spatially

430 expanded ocean climate data (Wang et al., 2018).

432 Sample collections throughout NAFO Divisions 2J, 3K, 3L, 3N, and $3 \mathrm{O}$ (Figure 1) occurred during 433 summer-fall while those from NAFO Subdivision 3Ps were taken during spring. Operating under an 434 assumption that the April-June seasonality of the spring collections near-fully conform with the post435 molting period for crab expected to be on near-annual molting schedules, seasonality differences in 
436 collections would not be expected to affect interpretations of age estimates in terms of chronologically

437 tracking annual time signatures as ages (i.e., crab collected in April versus October in a given year would

438 be expected to have formed their most-recent age band signature during the same molting period). However,

439 if the unknown band deposition mechanisms are related to seasonality factors independent of molting, there

440 could be bias created among the SDs by these temporal differences in sample collection times (i.e., if the

441 controlling mechanisms occurred during late spring or early summer, spring (3Ps) versus fall (2J3K, $3 \mathrm{LNO})$

442 collections could be disparate in comparison).

444 Where appropriate, quantitative field observation data from spring and fall multi-species trawl surveys in 445 offshore portions of the NL shelf were used in comparisons to growth dynamics observed in the specimens 446 used for aging. Briefly, these annual surveys form the cornerstone for stock assessments of numerous 447 commercial species in the NL Region, including snow crab. The surveys utilize a Campelen 1800 448 rockhopper shrimp trawl to randomly sample within a depth-stratified bathymetric design in fall (September 449 - December) in SDs 2J3K and 3LNO and spring (March-May) in SD 3Ps. The fall surveys began in 1995 450 and the spring surveys began in 1996. Further details on these trawl surveys are available in Baker et al. 451 (2021). Note that NAFO Division $2 \mathrm{H}$ data is included in survey information for SD ' $2 \mathrm{~J} 3 \mathrm{~K}$ ' herein but is 452 overall very minor, with crab not typically found far beyond the NAFO Division 2J boundary, and 453 particularly so in recent years.

455 All snow crab captured in the trawl surveys were sorted, counted, and fully- or sub-sampled at-sea. Data 456 were recorded on sex, size $(\mathrm{CW})$, shell condition, and maturity. $\mathrm{CW}(1 \mathrm{~mm})$ and right claw measurements 457 (0.1mm, males only) were taken using Vernier calipers. Shell condition was subjectively assigned to one 458 of five stages of soft, new, intermediate, old, and very-old shell (see Baker et al. (2021) for more details). 459 Soft- and new-shelled crab are assumed to have molted within the past year and there is an assumption that 460 post-molt time period increases are tracked with increasing shell condition stage thereafter, but not in an 461 explicitly quantitative way. Morphometric maturity of males was determined from the relationship of right 462 claw height to $\mathrm{CW}$ using the discrimination equation $\left[R C<\right.$ or $\left.>0.0806 * C W^{t .1999}\right]$ from the stock assessment 463 (Baker et al., 2021), where RC denotes right claw and CW denotes carapace width. Males with a missing 464 right claw or showing obvious signs of regeneration for that claw were omitted from maturity assessments. 465 Males with "small claws" $[<\mathrm{RC}]$ were characterized as immature/adolescent and those with "large claws" $466[>\mathrm{RC}]$ as adults. Morphometric maturity status of females was based on simple visual assessment of the 467 abdomen, with enlarged abdominal flaps indicative of mature animals. 
There were concerns that on-going spatial contractions within some areas of the stock range concomitant with abundance declines in the years preceding and including 2015 (i.e., Mullowney et al., 2020; Baker et al., 2021) could affect reliability of the "snap-shot" samples used in the aging experiment in reflecting longterm habitat contrasts invoked in using the SDs as a basis for spatial comparisons of differences in age and growth outcomes among heterogeneous ecosystems (Section 1.4). To address, a comparison of conformity

474 of depth- and temperature-at-capture for crab used in the aging study versus extended time series catches

475 of crab in the trawl surveys was conducted for $5 \mathrm{~mm} \mathrm{CW}$ groupings of both sexes. Mean annual depth- and

476 temperature-at-capture of crab for representative years extending back to 1996 were plotted alongside the

477 three most recent years (2013-2015) as well as the individuals used in the aging study. This enabled a

478 qualitative evaluation of the degree to which samples used in the aging study were representative of both

4792015 and long-term capture conditions, and more generally the extent to which contrasting habitat

480 conditions among SD ecosystem units had changed over time. The density of exploitable-size male crab in 481 each SD was also calculated for each SD and year to assess the extent to which this component of ambient 482 habitat conditions had changed over time both within and across SDs. To develop the density index, the 483 annual Exploitable Biomass Indices from the stock assessment (Baker et al., 2021) were divided by the 484 total areal coverage of the survey strata within each SD.

\subsection{Age Determination}

488 Crab used for age estimations were processed at the University of New Brunswick. All crab were measured 489 for size and maturity as per above descriptions of field survey collections, although shell conditions were 490 not determined because many of the shells had thawed and deteriorated during shipping. Age estimation 491 was based on gastric mill bands following methods of Kilada et al. (2012). The gastric mill was dissected 492 from the stomach and cleaned. Three sections of the gastric mill (zygocardiac, pterocardiac, and 493 mesocardiac ossicles) were separated for comparative age estimation, with each section embedded in a 494 5:1(volume) industrial epoxy-resin hardening mixture and dried for 48 hours before cutting with a low495 speed IsoMet saw.

497 Preliminary trials determined that best results for band interpretation from the zygocardiac and pterocardiac 498 ossicles resulted from a transverse cut at $400 \mu \mathrm{m}$ thickness, and subsequently viewed using reflected light. 499 Best images from the mesocardiac ossicles were found to occur from longitudinal cuts at a thickness of $500 \quad 100-200 \mu \mathrm{m}$, and subsequently viewed using transmitted light. Although age estimates were taken from 501 three locations of the gastric mill, as the study progressed it became evident that the zygocardiac ossicle 502 provided the clearest final images for counting bands, thus those age measurements were used in analyses. 
Observations were made with a SZX16 Olympus dissecting microscope and images were taken using a DP72 Olympus camera attached to the microscope. Images were enhanced using Adobe Photoshop before counting age bands. Age bands were visually distinguished from chitinous band lines within the endocuticle as being thicker, continuous, and evenly-spaced bands that could be seen from one side of the ossicle to the other without fading (Figure 2).

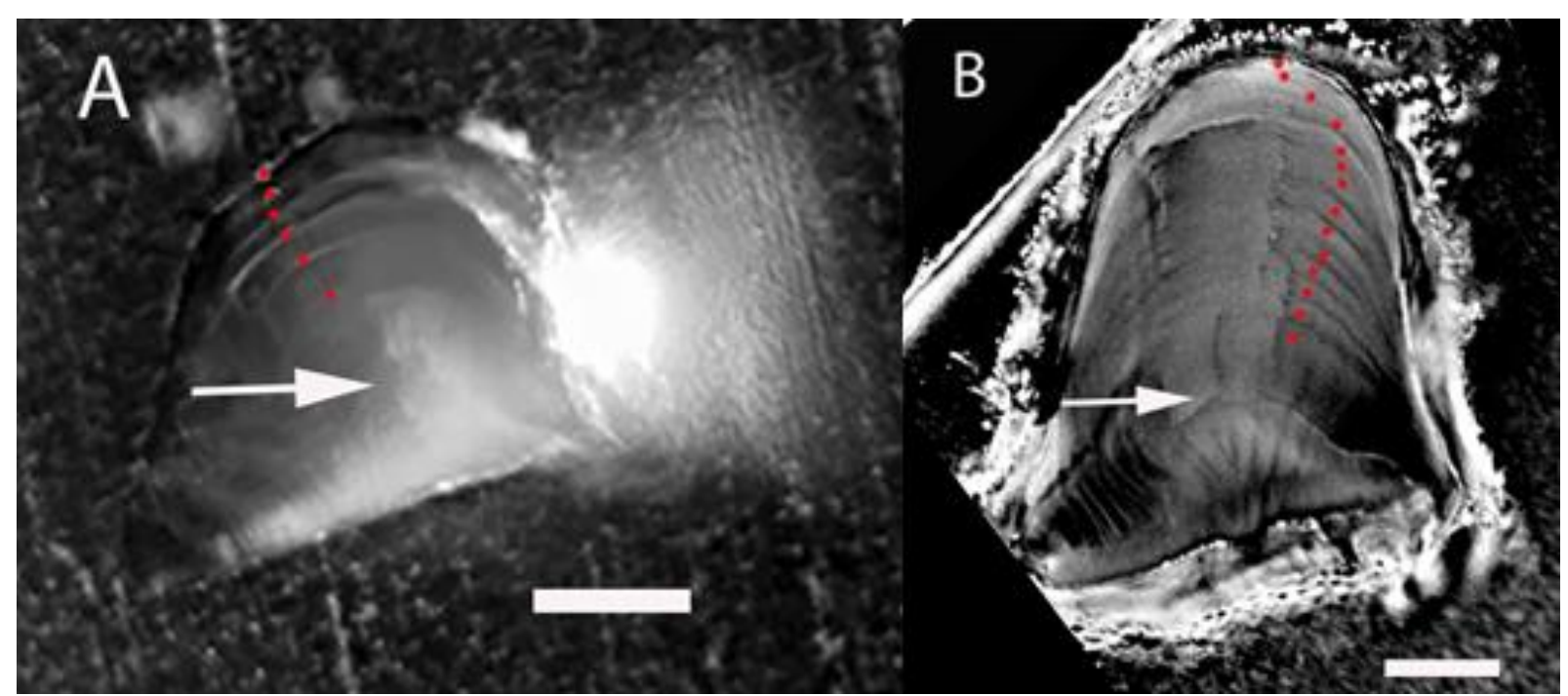

Figure 2. Transverse thin sections of zygocardiac ossicle of snow crab male individuals showing age $\mu \mathrm{m}$. (A) $23.4 \mathrm{~mm} \mathrm{CW}$ (6 age bands), and (B) $121.4 \mathrm{~mm} \mathrm{CW}$ (14 age bands).

A bias check for reading accuracy by the primary age reader was done by having comparative readings conducted by an independent reader with no prior knowledge on crab size, sex, or other attributes, for 38 random samples (Catlin, 2020). A check on raw age estimation data showed no systematic or significant reader bias, with high (linear) correlation $\left(\mathrm{R}^{2}=0.97\right)$ following a simple model fit of the form [primary reader $\sim 0.96 *$ independent reader].

\subsection{Estimated Size-at-Age and Age-at-Maturity}

Age was represented by gastric mill band count. For visual interpretations, SD-specific size-at-age scatterplots were fit with Generalized Additive Models (GAM) with the MGCV package (Wood, 2017) in $\mathrm{R}$ version 4.0.2. ( $\mathrm{R}$ core team, 2020). GAM was chosen over Von Bertalanaffy growth curves due to evidence of non-asymptotic growth and associated poorer fits in the Von Bertalanaffy models in SD 3Ps crab samples. Exploratory analyses of model families and link functions showed little difference among gaussian and gamma families or log and identity links. A gamma family distribution with a log link function 
was used as it was assumed the growth process would follow a positive and continuous but occasionally interrupted process that would exhibit logistic growth pattern tendencies toward an asymptote as maximum sizes were approached. The models were fit using a thin-plate smoothing spline on the single independent variable of age, for both sexes. Growth models were initially developed for each sex based on immature and mature individuals, but additional size-at-age models were developed for only immature/adolescent males to enable direct comparison with predicted sizes for immature/adolescent males from the nGSL (NAFO Division 4S, Figure 1).

For statistical testing of differences in size-at-age among NL SDs, generalized linear models (GLM) were applied to the raw data [CW age + division]. For both sexes, gamma family distributions and log link functions were used. Post-hoc comparisons and significance testing of pairwise differences in size-at-age among SDs were conducted through analysis of estimated marginal means (i.e. least squares means) (Searle et al., 1980) in the Emmeans package (Lenth, 2021) in $R$. Contrast ratios and probability estimates of pairwise (SD) differences were determined via the default adjustment to studentized Tukey range distributions and assessed at the $\mathrm{p}=0.05$ level. Point estimates and associated confidence intervals for mean ages used in any given analysis were plotted for presentation and odds ratios (the outcome per unit increase in the explanatory variable) of specific pairwise comparisons were reported to interpret contrast across SDs.

A comparison of size-at-age between the sexes was conducted for two separate size groups with a break at $40 \mathrm{~mm} \mathrm{CW}$. This size group separation was done to relate the analysis to the literature which suggests there should be no difference in size-at-age between the sexes up to instar VIII (i.e. the $\leq 40 \mathrm{~mm}$ CW size group) while separation between the sexes would be likely to occur thereafter as females begin to terminally molt more commonly (at earlier instar stages) than males. For each statistical test a model of the form [CW age + division + sex] was run in a GLM featuring a gamma family distribution and log link, and post-hoc comparisons of sexes both within and among SDs was conducted via estimated marginal means. Females were excluded from SD 3Ps in the $>40 \mathrm{~mm}$ CW test due to small sample size.

Age-at-maturity ogives were derived for SD-sex pairings using GAMs featuring a smooth spline effect of 557 age fit against a binomial response variable of maturity (logit link) for visual interpretation of age-at558 maturity trends. A GLM with a binomial family distribution and a logit link was used to test for age-at559 maturity differences between SDs [maturity age + division] for males, followed by analysis of estimated 560 marginal means for post-hoc pairwise comparisons as described for size-at-age analyses. Similar tests were 561 not possible for females due to data deficiencies, with no mature females captured in SD 3Ps and insufficient 562 sample sizes across the age spectrum in SD 2J3K. 
564 A comparison of age-at-maturity between the sexes was conducted in SD 3LNO, where data sufficed. 565 Again, a binomial family distribution with a logit link was used in a GLM of the form [maturity $\sim$ age +

566 sex] and estimated marginal means were used for post-hoc pairwise comparisons for differences across 567 SDs.

569 To address whether or not gastric mill bands accrued after terminal molt (i.e. Rebert et al., 2020), pairwise 570 comparisons of mean ages for mature (adult) versus immature (sub-adult) crab within $5 \mathrm{~mm} \mathrm{CW}$ bins were 571 calculated. The analysis was restricted to the $40-60 \mathrm{~mm} \mathrm{CW}$ range for females and the $55-105 \mathrm{~mm} \mathrm{CW}$ range 572 for males because these were the sizes over which immature and mature crab overlapped. Only size bins 573 with at least two mature and two immature crab age estimates were plotted. The point estimates of mean 574 ages for each maturity group and size bin were plotted, along with differences in mean age values (mature 575 -immature) within each size bin. The assumption was that if gastric mill bands did not accrue after terminal 576 molt, the differences in mean ages of same-size immature and mature crab should be minimal (near zero).

577 Conversely, if gastric mill bands continued to form after terminal molt, the differences between mean ages 578 would be expected to be well above zero (older in mature crab), potentially extending up to a maximum of 579 five-six years (assuming this is a reasonable estimate of typical post-terminal molt longevity in unfished 580 populations). Females were expected to most clearly show the magnitude of differences in mean ages 581 between mature versus immature crab because they would not have skip-molted or been subjected to 582 fisheries-induced mortality (or minimally for both factors in comparison to males). For males, the 583 expectation was that differences in mean ages between mature and immature crab should be most obvious 584 at smaller sizes within the examined size range. This expectation is because males would be progressively 585 subjected to higher levels of fisheries mortality (including discard mortality of $<95 \mathrm{~mm} \mathrm{CW}$ crab) as they 586 approached legal-size.

\subsection{Molt Frequency}

Instars were assigned to the aged crab to investigate molt frequency dynamics. Instars were determined

592 males presented in Table 1 in Sainte-Marie et al. (1995) (Figure 1). A closest neighbour approach based on 593 size was used to assign instars to the aged crab specimens. For example, a crab measured at $24 \mathrm{~mm} \mathrm{CW}$ in 594 our study was assigned as instar VI, being closer to the $21.02 \mathrm{~mm} \mathrm{CW}$ modal size for this instar than the $59528.48 \mathrm{~mm}$ CW modal size for instar VII in Sainte-Marie et al. (1995). 
597 Prior to assigning instars to the aged specimens, we partially validated the approach by visually comparing

598 size-frequency distributions of $\leq 45 \mathrm{~mm} \mathrm{CW}$ crab from NL multi-species trawl surveys from 1995-2020 to

599 the modal instar sizes assigned by Sainte-Marie for crab in the nGSL. Sizes beyond $45 \mathrm{~mm} \mathrm{CW}$ in the trawl

600 surveys were not deemed reliable for modal differentiation as there were no obvious peaks. This was

601 anticipated and in-part reflects poor catchability of intermediate-sized snow crab by the survey trawl (Dawe

602 et al., 2010; Baker et al., 2021) along with increasing spread in size around instar modes after these stages

603 (Yamamoto et al., 1998a; Sainte-Marie et al., 2021). Nonetheless, given tight conformity of NL crab with

604 nGSL crab up to instar VIII, and tight association with nGSL estimates with those reported in Ito (1970)

605 for the Sea of Japan over the full size range of males, it was deemed reasonable to assume NL crab larger

606 than $45 \mathrm{~mm} \mathrm{CW}$ would sufficiently maintain general conformity with size-at-instar with the nGSL

607 predictions for the spatial comparisons.

609 In order to associate estimated ages with the number of molts accrued, an index of age-at-instar was 610 developed for males in each SD. This analysis was restricted to males because of the broader size spectrum, 611 greater incidence of skip-molting, and the ability to make direct comparisons to the nGSL "control" 612 population. For NL SDs, means and standard deviations of age-at-instar were calculated for 613 immature/adolescent males and plotted alongside the historic nGSL observations. Adult males were 614 excluded as they had undergone their terminal molt.

616 Finally, in order to qualitatively compare size-at-age and age-at-maturity outcomes in the aged crab with 617 trends occurring in the wild, proportional molt status for crab deemed to have either molted or skip-molted 618 within the current year were calculated for each SD in the trawl survey field data for the 2006-2015 period.

619 Molt-type outcomes in the wild crab were determined based on maturity status and shell conditions, with 620 immature/adolescent males in a soft- or new-shell condition assigned as having undertaken a regular molt, 621 immature/adolescent males in an intermediate- or old-shell condition assigned as skip-molters, and adults 622 in a soft- or new-shell condition assigned as having undergone terminal molt during the most recent molting 623 period. Intermediate and older shell adults (i.e. terminally molted) were excluded as not having recently 624 molted or skip-molted. Instar sizes were applied to the survey field data in the same fashion as previously 625 described for the aged crab specimens, via a closest neighbour approach based on predicted modal instar 626 sizes reported by Sainte-Marie et al. (1995). 


\subsection{Surveys}

634 The overall distributional patterns of habitat characteristics for both sexes in SD 2J3K in most years was

635 for smallest crab $(<12 \mathrm{~mm} \mathrm{CW})$ to be commonly found in relatively warm water $\left(\sim 2-4^{\circ} \mathrm{C}\right)$ in deep areas $(\sim$ $636200-400 \mathrm{~m})$ while moderate-sized crab $(12-50 \mathrm{~mm} \mathrm{CW})$ were on-average found in colder $\left(\sim 0-2^{\circ} \mathrm{C}\right)$ 637 shallower ( 200-300m) waters (Figure 3). Within this general pattern, over the circa 2002-2015 period, 638 there was a trend of these moderate-sized crab being captured in progressively shallower and colder water. However, counter to this long-term trend, the moderate-sized specimens taken in 2015 for the ageing component of this study were captured at or near the upper end of historic temperature $\left(\sim 4-5^{\circ} \mathrm{C}\right)$ and depth $(\sim 300 \mathrm{~m})$ ranges. Above $50 \mathrm{~mm} \mathrm{CW}$, crab of both sexes used in the aging study overall closely conformed to natural sampled distributions, showing a consistent spatial stratification pattern reflecting progressive deepening and warming with size (largest crab of both sexes caught in $\sim 300-400 \mathrm{~m}$ depth and $\sim 3-4^{\circ} \mathrm{C}$ ) that occurred in most years. The density of exploitable males (i.e., > x mm CW) was consistently lowest in this SD, near or below 500 crab per square nautical mile since 2000, with particularly low densities of about $250 \mathrm{crab}$ per square nautical mile in recent years.

SD 3LNO most clearly showed a spatial contraction of large crab $(>50 \mathrm{~mm} \mathrm{CW})$ toward shallower and colder water throughout the time series, with the pattern most evident in males (Figure 3). In both sexes, 2015 distributions were on-average at or near historic lows for both depth and temperature. The majority of large crab of both sexes were caught in depths of about $\sim 150 \mathrm{~m}$ and temperatures of about $\sim-1{ }^{\circ} \mathrm{C}$ in 2015. The specimens used for aging generally reflected this pattern, although there was considerable

653 variability in both directions around the 2015 survey means for both depth and temperature for all size 654 groupings of crab. SD 3LNO consistently showed the highest densities of exploitable males among SDs 655 throughout the time series, with greater than $1000 \mathrm{crab}$ per square nautical mile estimated in all but a few 656 years (Figure 3). However, like all SDs, recent years have been associated with time series lows in the 657 density index, with just 500 crab per square nautical mile estimated in 2015 . In context of the time period 658 of 15-20 years during which virtually all crab for the aging study would have inhabited the SD 3LNO 659 ecosystem, the long-term habitat conditions have reflected our ecosystem unit generalizations of reflecting 660 ambient conditions indicative of an intermediate level of access to warm water and high population densities 661 of large males relative to other SDs. However, in the most recent years, and in particular in 2015 when our 662 crab were acquired for ageing, this has not been the case. In most recent years, SD 3LNO crab have been 663 captured in similarly cold conditions as SD 3Ps and densities of large males have been relatively low. 

that would be expected to be most frequently molting.
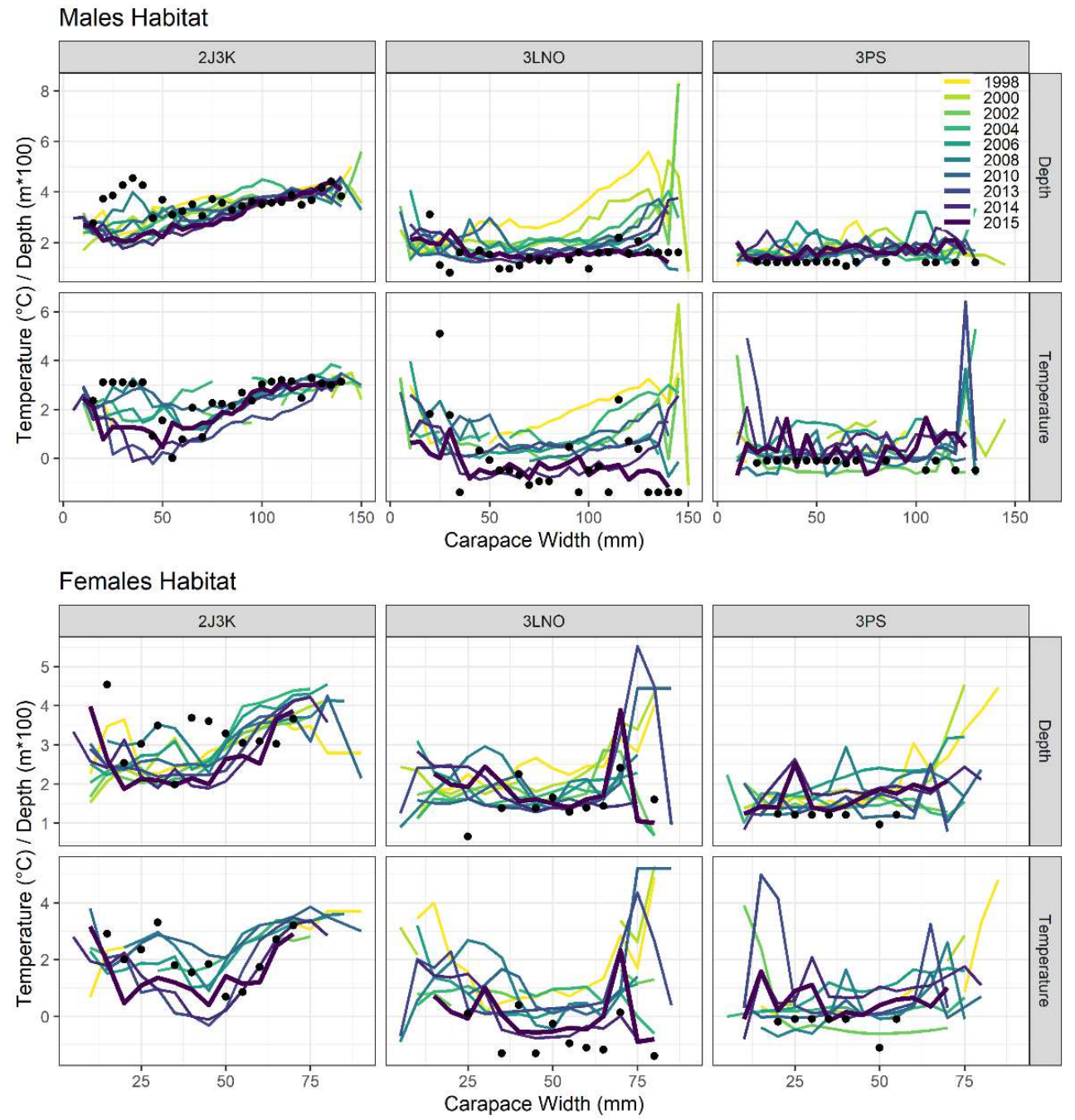

Exploitable Male Density Index
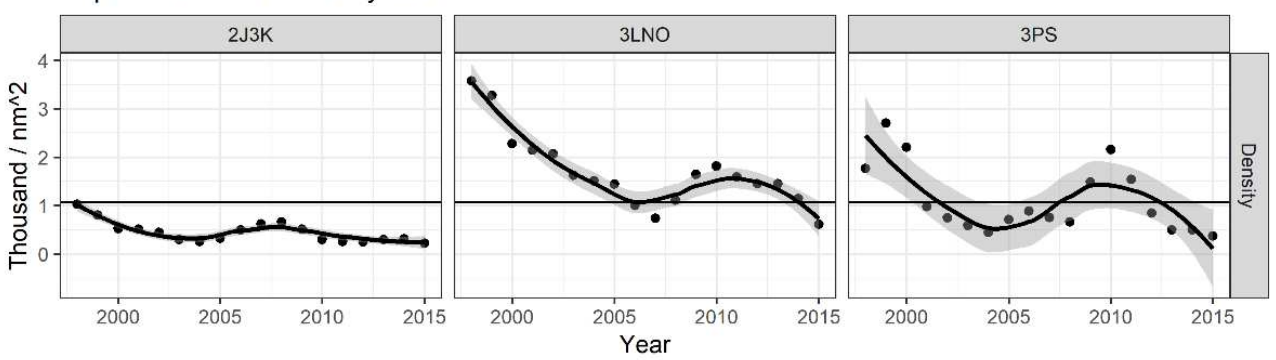

Figure 3. Upper two Panel Groups: Depth- and temperature-at-capture profiles for $5 \mathrm{~mm} \mathrm{CW}$ crab groups captured in trawl surveys for select years during the 1998-2015 period. Lines show means. Black dots show means of depth- and temperature-at-capture for samples collected for the 2015 aging study. Bottom Panels: Exploitable-size $(\geq 95 \mathrm{~mm} C W)$ male density index by year and Study Division. Points show annual estimates and line is a loess regression curve fit to the annual estimates. Gray bands show $95 \%$ confidence intervals of fit of regressions to the point estimates. 
674 Our assumptions of SD 3Ps crab being exposed to an ecosystem featuring overall coldest conditions and

675 moderate densities of large males were well supported by the survey time series observations on depth- and

676 temperature-at-capture as well as estimates of exploitable male denisty (Figure 3). Overall, with the

677 occassional sporadic incidence of largest crab of either sex being caught deep (> 200m depth) and warm

$678\left(>\sim 2^{\circ} \mathrm{C}\right)$, most crab here have consistently been captured in $100-150 \mathrm{~m}$ depth and $0-1{ }^{\circ} \mathrm{C}$, particularly in the

679 most recent decade, and the aging specimens reflected this overall pattern. In most years since 2000, the

680 500-1000 exploitable male crab per square nautical mile represent intermediate values relative to SDs 2 J3K

681 and $3 \mathrm{LNO}$.

682

683 Overall, the specimens used in the aging study were deemed to fit within the scope of assumptions used for 684 geographic partitioning of heterogenous ecosystem units among SDs. The most notable exceptions were 685 warmer than normal capture conditions for moderate-sized crab specimens in SD 2J3K, an obvious 686 progressive contraction of geographic disiributions of crab in SD 3LNO toward shallow and cold habitats 687 within the lifetime most crab subjects inhabited that ecosystem, and atypically cold distribution conditions 688 for SD 3LNO crab in recent years.

\subsection{Estimated Size-at-Age and Age-at-Maturity}

\subsubsection{Size-at-Age by Sex}

Overall, the GAM curves fit the estimated age by size data relatively well for both crab genders in all three SDs (Figure 4). Adjusted r-squared values were $0.65,0.48$, and 0.76 for males, and $0.56,0.53$, and 0.37 for

700 GAM-modeled growth rates of males in SDs 2J3K and 3LNO were very similar across the entire estimated 701 age range (Figure 5). Both SDs showed a relatively constant growth rate up to about 85-95mm CW and 970210 years estimated age, at which point growth slowed (reflecting increasing proportions of adults in the 703 data) until maximum size of approximately $125 \mathrm{~mm} \mathrm{CW}$ at an estimated 16-18 years of age. In contrast, 704 males in SD 3Ps showed a markedly different growth pattern, featuring a similar, albeit delayed, growth 705 pattern to the nGSL adolescent male crab, with a progressively increasing growth rate slope over the entire 706 estimated age spectrum (Figure 5). On-average, males were estimated to reach legal fishery size of $95 \mathrm{~mm}$ $707 \mathrm{CW}$ at 10 years of age in SDs $2 \mathrm{~J} 3 \mathrm{~K}$ and $3 \mathrm{LNO}$ and 12 years of age in SD 3Ps. 


\section{Morphometrics * Adult $\circ$ Sub-Adult}
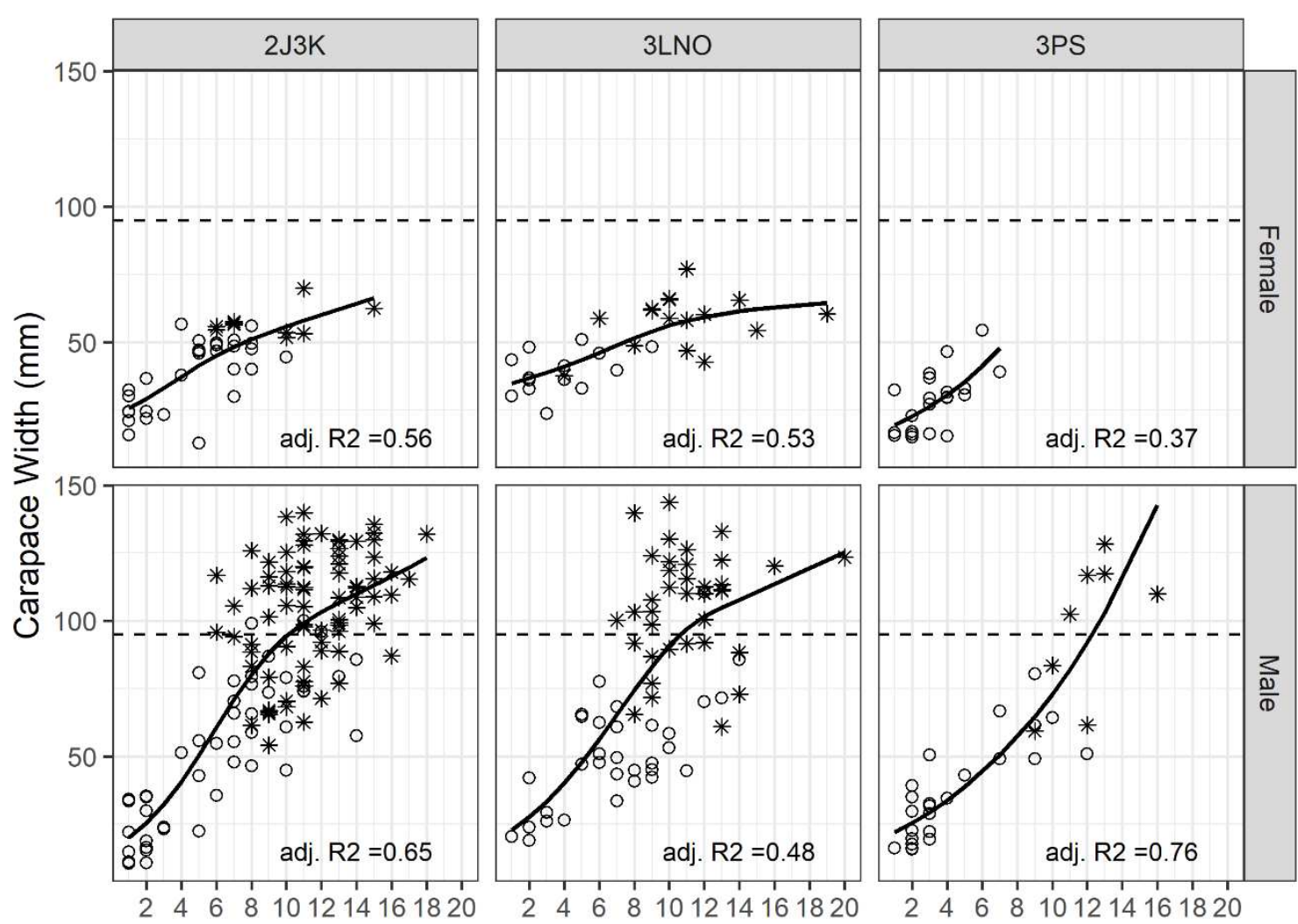

Figure 4. GAM functions fit to size-at-estimated-age data for male and female snow crab sampled from our three Study Divisions. Horizontal dashed line shows minimum legal fishery size. Adult crab shown by stars and sub-adult crab shown by open circles.

713 The GLM on male CW expectedly showed age to be a significant predictor of size (Table 1, p<0.0001).

714 Pairwise comparisons among SDs showed significant differences in estimated size-at-age between SD 3Ps 715 and both $2 \mathrm{~J} 3 \mathrm{~K}(\mathrm{p}=0.01)$ and $3 \mathrm{LNO}(\mathrm{p}=0.01)$, but no difference between $2 \mathrm{~J} 3 \mathrm{~K}$ and $3 \mathrm{LNO}(\mathrm{p}=0.96)$ (Table

716 1). The odds ratios of sizes in males in SDs $2 \mathrm{~J} 3 \mathrm{~K}$ and $3 \mathrm{LNO}$ relative to 3Ps were about 1.2 over the age 717 spectrum, and by age 9 (point estimate of 8.9 years) there were significant differences in mean sizes of 3Ps 718 males compared to the other two SDs (Figure 5). 
Table. 1. Results of GLMs of (i) size-at-age for male and female crab from our three study Divisions, (ii) age-at-maturity for males (insufficient data for females) from our three study Divisions, (iii) size-at-age by sex for $\leq 40 \mathrm{~mm} \mathrm{CW}$ and $>40 \mathrm{~mm} \mathrm{CW}$ crab groups, and (iv) age-at-maturity of males versus females in Division 3LNO (insufficient data on females in other two divisions). Ref Div. refers to reference division. Associated marginal means and pairwise test results shown in Figure 6.

\begin{tabular}{|c|c|c|c|c|c|c|c|}
\hline Dep. Var. & $\begin{array}{c}\text { Sex } \\
\text { [Division] }\end{array}$ & Indep. Var. & Estimate & $\begin{array}{l}\text { Std. } \\
\text { Err. }\end{array}$ & tor $z$ & $\mathrm{p}$ & $\begin{array}{l}\text { Ref. Div. } \\
\text { [Ref. Sex] }\end{array}$ \\
\hline Size $(C W)$ & $M$ & Intercept & 3.29 & 0.06 & 53.51 & $<0.0001$ & \\
\hline Size (CW) & $M$ & Age & 0.11 & 0.01 & 19.95 & $<0.0001$ & \\
\hline Size $(C W)$ & $M$ & Div2J3K & -0.01 & 0.05 & -0.26 & 0.96 & 3LNO \\
\hline Size (CW) & $\mathrm{M}$ & Div2J3K & 0.20 & 0.07 & 2.80 & 0.01 & $3 P s$ \\
\hline Size $(C W)$ & $\mathrm{M}$ & Div3LNO & 0.22 & 0.08 & 2.79 & 0.01 & 3Ps \\
\hline Size (CW) & $\mathrm{F}$ & Intercept & 3.37 & 0.06 & 53.87 & $<0.0001$ & \\
\hline Size (CW) & $\mathrm{F}$ & Age & 0.06 & 0.01 & 7.87 & $<0.0001$ & \\
\hline Size (CW) & $\mathrm{F}$ & Div2J3K & -0.04 & 0.07 & -0.65 & 0.79 & 3LNO \\
\hline Size (CW) & $\mathrm{F}$ & Div2J3K & 0.25 & 0.07 & 3.41 & 0.002 & $3 \mathrm{Ps}$ \\
\hline Size (CW) & $\mathrm{F}$ & Div3LNO & 0.29 & 0.08 & 3.60 & 0.001 & $3 P s$ \\
\hline Size $(C W) \leq 40 \mathrm{~mm}$ & $\mathrm{M}$ & Intercept & 3.07 & 0.09 & 35.97 & $<0.0001$ & \\
\hline Size $(C W) \leq 40 \mathrm{~mm}$ & M & Age & 0.07 & 0.02 & 3.71 & 0.0004 & \\
\hline Size $(C W) \leq 40 \mathrm{~mm}$ & $\mathrm{M}$ & Sex & -0.09 & 0.07 & -1.37 & 0.17 & {$[\mathrm{~F}]$} \\
\hline Size $(C W)>40 \mathrm{~mm}$ & $\mathrm{M}$ & Intercept & 3.59 & 0.06 & 60.00 & $<0.0001$ & \\
\hline Size $(C W)>40 \mathrm{~mm}$ & $M$ & Age & 0.05 & 0.01 & 9.17 & $<0.0001$ & \\
\hline Size $(C W)>40 \mathrm{~mm}$ & $\mathrm{M}$ & Sex & 0.42 & 0.04 & 9.87 & $<0.0001$ & {$[F]$} \\
\hline Maturity & $\mathrm{M}$ & Intercept & -4.38 & 0.71 & -6.17 & $<0.0001$ & \\
\hline Maturity & $M$ & Age & 0.53 & 0.07 & 7.28 & $<0.0001$ & \\
\hline Maturity & $M$ & Div3LNO & 0.31 & 0.39 & -0.80 & 0.70 & 3LNO \\
\hline Maturity & M & Div3Ps & 1.15 & 0.62 & -1.87 & 0.15 & $3 \mathrm{Ps}$ \\
\hline Maturity & M & Div3Ps & 0.85 & 0.64 & -1.32 & 0.38 & $3 \mathrm{Ps}$ \\
\hline Maturity & [3LNO] & Intercept & -3.92 & 0.95 & -4.22 & $<0.0001$ & \\
\hline Maturity & [3LNO] & Age & 0.58 & 0.11 & 5.07 & $<0.0001$ & \\
\hline Maturity & [3LNO] & Male & 1.19 & 0.68 & -1.74 & 0.08 & {$[\mathrm{~F}]$} \\
\hline
\end{tabular}

733 Small sample sizes and a more limited size range likely affected model-estimated patterns of growth in

734 females moreso than in males, but the female models nevertheless also showed more similar growth in SDs

$7352 \mathrm{~J} 3 \mathrm{~K}$ and $3 \mathrm{LNO}$ than in 3Ps. The relatively large estimated size in estimated age 2 females in 3LNO

$736(\sim 35 \mathrm{~mm} \mathrm{CW})$ almost certainly reflects insufficient data $(\mathrm{n}=6$ females $\leq 2$ years old $)$, and no females above

737 estimated age 8 were present in the Division 3Ps data (Figure 6). Nevertheless, female size-at-age was

738 similar in SDs 2J3K and 3LNO over estimated ages 6-12, during which time sizes gradually increased from

739 about 40 to $60 \mathrm{~mm} \mathrm{CW}$. In contrast, female growth rates in SD 3Ps progressively increased over the limited 

ages 1-5, before reaching a similar level of about $40 \mathrm{~mm} \mathrm{CW}$ at estimated age 6 .

743
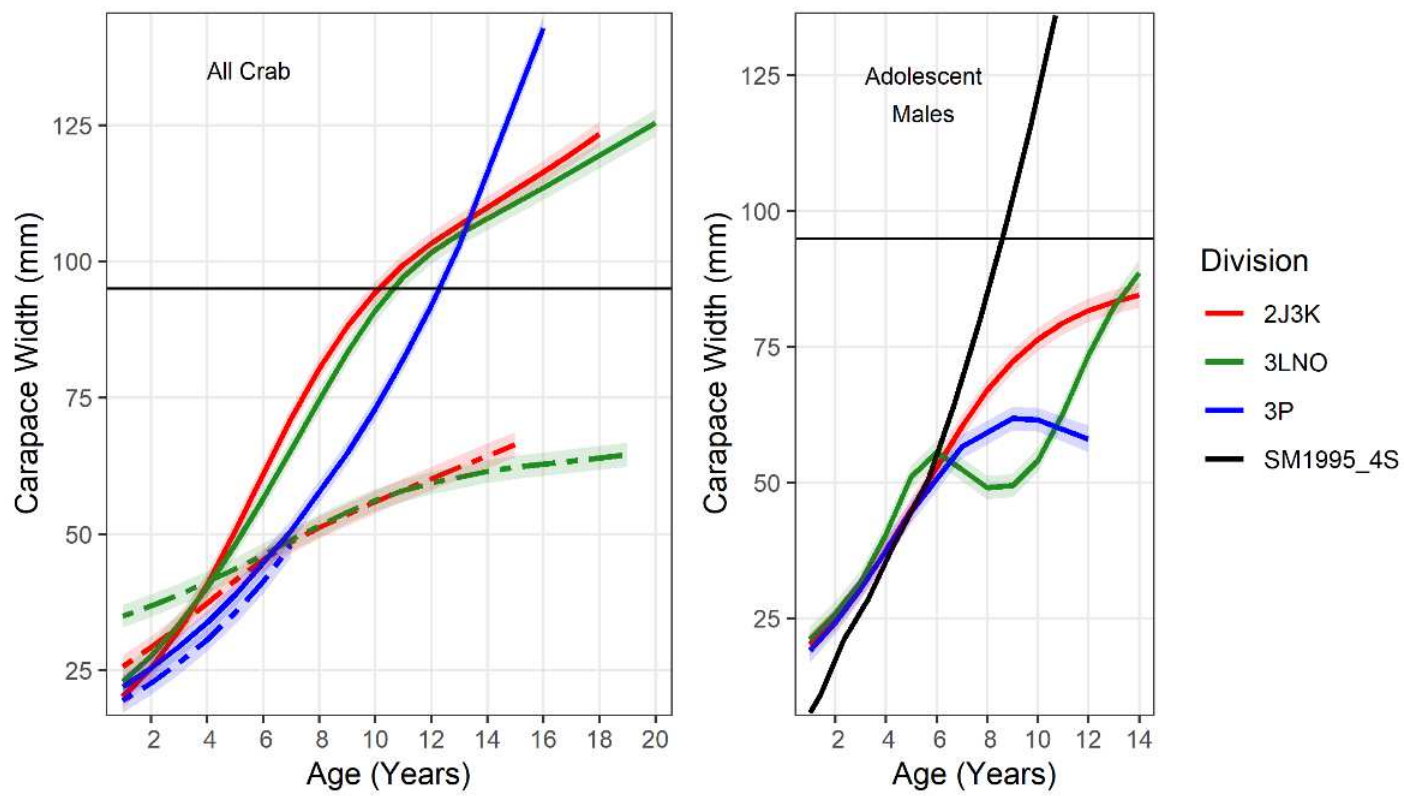

Figure 5. GAM model fits of size-at-age data for all male and female snow crab (left) and immature/adolescent males (right) in different Study Region in NL (red, blue and green lines) and in the nGSL (black line, from Sainte-Marie et al. 1995). Note that NL and nGSL age data were recorded on an annual and a monthly basis, respectively, reflecting frequency of collections. Solid horizontal lines show legal fishery size $(95 \mathrm{~mm} \mathrm{CW})$.

The GLM on female CW similarly showed age to be a significant predictor of size (Table 1, p<0.0001) and pairwise comparisons among SDs were consistent in showing significant differences in estimated size-atage between SD 3Ps versus both 2J3K $(\mathrm{p}<0.01)$ and 3LNO $(\mathrm{p}<0.001)$, but no difference between $2 \mathrm{~J} 3 \mathrm{~K}$ and $3 \mathrm{LNO}(\mathrm{p}=0.79$ ) (Table 1). The odds ratios of size differences over the age spectrum for SD 2J3K and 3LNO crab relative to 3Ps crab were both about 1.3, and there were significant differences in mean sizes of 3Ps crab with the other two SDs by age 6 (estimated age 5.8 years) (Figure 6).

Across-sex comparisons of size-at-age were affected by sample size limitations in all SDs, which likely affected model fits, including limited (SD 2J3K) or no (SD 3Ps) samples of mature females and scarcity of youngest (immature) crab of both sexes (estimated ages 1-3, SD 3LNO). Nonetheless, with both maturity groups pooled the data were deemed sufficient to qualitatively interpret across-sex differences over the entire age spectrum of SD 2HJ, beyond age 3 in SD 3LNO, and below age 8 in SD 3Ps. Overall, it is apparent that across-sex divergence in size-at-age began after estimated age 4 in SDs 2J3K and 3LNO, with the growth rate curves in females more restricted than that of males and gradually dampening thereafter 
765 (Figure 5) and presumably reflecting the earlier maturation of females. By estimated age 14, males were 766 about $50 \mathrm{~mm} \mathrm{CW}$ larger than females on-average (110 vs. $60 \mathrm{~mm} \mathrm{CW})$ in both SDs $2 \mathrm{~J} 3 \mathrm{~K}$ and $3 \mathrm{LNO}$. The 767 immature females in 3Ps were only marginally smaller at any given size than their male counterparts, all of 768 which were also immature/adolescent, over the entire estimated age 1-7 range. Overall, despite sample size

769 limitations, it is apparent that female size-at-age is lower than that of males for part of the age spectrum 770 within at least some SDs (SDs 2J3K and 3LNO).

772 Table. 2. Results of pairwise comparisons for GLMs of size-at-age by sex for $\leq 40 \mathrm{~mm}$ CW and $>40 \mathrm{~mm}$ 773 CW crab groups. Associated marginal means and pairwise test results for sex shown in Figure 6.

\begin{tabular}{|c|c|c|c|c|c|}
\hline Group & Contrast & Estimate & Odds Ratio & Z & $\mathrm{p}$ \\
\hline$\leq 40 \mathrm{~mm} \mathrm{CW}$ & $\mathrm{F} 2 \mathrm{~J} 3 \mathrm{~K}-\mathrm{M} 2 \mathrm{~J} 3 \mathrm{~K}$ & 0.09 & 1.10 & 1.37 & 0.75 \\
\hline$\leq 40 \mathrm{~mm} \mathrm{CW}$ & F2J3K - M3LNO & -0.04 & 0.96 & -0.34 & 1.00 \\
\hline$\leq 40 \mathrm{~mm} \mathrm{CW}$ & F2J3K - M3Ps & 0.09 & 1.09 & 0.81 & 0.97 \\
\hline$\leq 40 \mathrm{~mm} \mathrm{CW}$ & M2J3K - F3LNO & -0.23 & 0.80 & -1.98 & 0.35 \\
\hline$\leq 40 \mathrm{~mm} \mathrm{CW}$ & M2J3K - F3Ps & -0.10 & 0.91 & -1.04 & 0.91 \\
\hline$\leq 40 \mathrm{~mm} \mathrm{CW}$ & F3LNO - M3LNO & 0.09 & 1.10 & 1.37 & 0.75 \\
\hline$\leq 40 \mathrm{~mm} \mathrm{CW}$ & F3LNO - M3Ps & 0.22 & 1.25 & 1.86 & 0.43 \\
\hline$\leq 40 \mathrm{~mm} \mathrm{CW}$ & M3LNO - F3Ps & 0.03 & 1.03 & 0.29 & 1.00 \\
\hline$\leq 40 \mathrm{~mm} \mathrm{CW}$ & F3Ps - M3Ps & 0.09 & 1.10 & 1.37 & 0.75 \\
\hline$>40 \mathrm{~mm} \mathrm{CW}$ & $F 2 J 3 K-M 2 J 3 K$ & -0.42 & 0.66 & -9.87 & $<0.0001$ \\
\hline$>40 \mathrm{~mm} \mathrm{CW}$ & F2J3K - M3LNO & -0.38 & 0.68 & -6.72 & $<0.0001$ \\
\hline$>40 \mathrm{~mm} \mathrm{CW}$ & F2J3K - M3Ps & -0.23 & 0.79 & -3.18 & 0.02 \\
\hline$>40 \mathrm{~mm} \mathrm{CW}$ & M2J3K - F3LNO & 0.46 & 1.60 & 8.63 & $<0.0001$ \\
\hline$>40 \mathrm{~mm} \mathrm{CW}$ & F3LNO - M3LNO & -0.42 & 0.66 & -9.87 & $<0.0001$ \\
\hline$>40 \mathrm{~mm} \mathrm{CW}$ & F3LNO - M3Ps & -0.27 & 0.76 & -3.7 & $<0.01$ \\
\hline
\end{tabular}

777 The GLM tests on $<40 \mathrm{~mm}$ CW crab confirmed that there was no significant difference in size-at-age 778 between the sexes in this size grouping (Table $1, \mathrm{p}=0.17$ ), which was not expected to be associated with 779 terminal molt in either sex. The lack of difference between the sexes reflected insignificant differences 780 ( $>$ >0.05) in all sex-SD pairings (Table 2). Despite lack of significance, females were overall slightly larger 781 than males in this size group of crab (odds ratio 1.1 F:M, Figure 6), which likely reflected some unusually 782 large females at young ages in SD 3LNO in particular (Figure 5). In contrast to the GLM tests on $\leq 40 \mathrm{~mm}$ 
$783 \mathrm{CW}$, the results of the $>40 \mathrm{~mm} \mathrm{CW}$ test on size-at-age variation between the sexes showed there were 784 significant differences (Table $1, \mathrm{p}<0.0001$ ) in this group of crab in which divergence in timing of stages at 785 the onset of terminal molt occurs. The significant difference between the sexes, with males much larger 786 than females at estimated age (Figure 6), reflected significant differences $(\mathrm{p}<0.01)$ in all sex-SD pairings 787 with the exception of a relatively modest difference in size between females in SD 2J3K and males in SD 788 3Ps ( $\mathrm{p}=0.02$, odds ratio 0.79$)$.

\subsubsection{Size-at-Age in Adolescent Males}

The GAM models suggest that immature/adolescent males in all NL SDs grew at a similar rate as those in the nGSL from estimated ages 4 to 6 , with sizes in all four SDs ranging about 50-55mm CW at estimated age 6 (Figure. 5). However, growth patterns diverged thereafter, with evidence of slower growth rates in all NL crab compared to nGSL crab. Notwithstanding a nonsensical decrease in growth in 3LNO males between ages 6 and 10, likely reflecting data limitations, the greatest reduction in growth rate of larger adolescent males appeared to occur in SD 3Ps, with adolescent males over estimated ages 8-12 averaging 55-60mm CW compared to 70-80 mm for $2 \mathrm{~J} 3 \mathrm{~K}$ males. SD 3LNO crab "caught up with" $2 \mathrm{~J} 3 \mathrm{~K}$ crab at ages 13-14. The overall asymptotic growth patterns in adolescent males in NL SDs after age 6 suggests that protracted molting frequencies in these crab overall renders smaller size-at-age in NL crab relative to those in the nGSL.

The larger sizes of estimated 1-3 year old immature males in the NL SDs relative to the nGSL are not fully understood. However, it does partially reflect models fitting to a higher degree of variability in the NL data. For example, across all SDs, the range of sizes for crab estimated at age 2 in NL was 11 to $42 \mathrm{~mm} \mathrm{CW}$ (Figure 4), with an average of $24.5 \mathrm{~mm}$ and a sample standard deviation (sSD) of $9.3 \mathrm{~mm}$ (Coefficient of 808 sample sSD of $0.92 \mathrm{~mm}$ and $1.33 \mathrm{~mm}(\mathrm{CVs}=0.06$ and 0.07$)$ at ages 1.8 and 2.3 years, respectively (Table 809 1, Sainte-Marie et al., 1995). The 24.5mm CW average size at age 2 in NL SDs most closely associates 810 with an observed mode at $26.9 \mathrm{~mm} \mathrm{CW}$ at age 3.3 in the nGSL data. The underlying reasons for this age 18113 estimation divergence requires further study. 

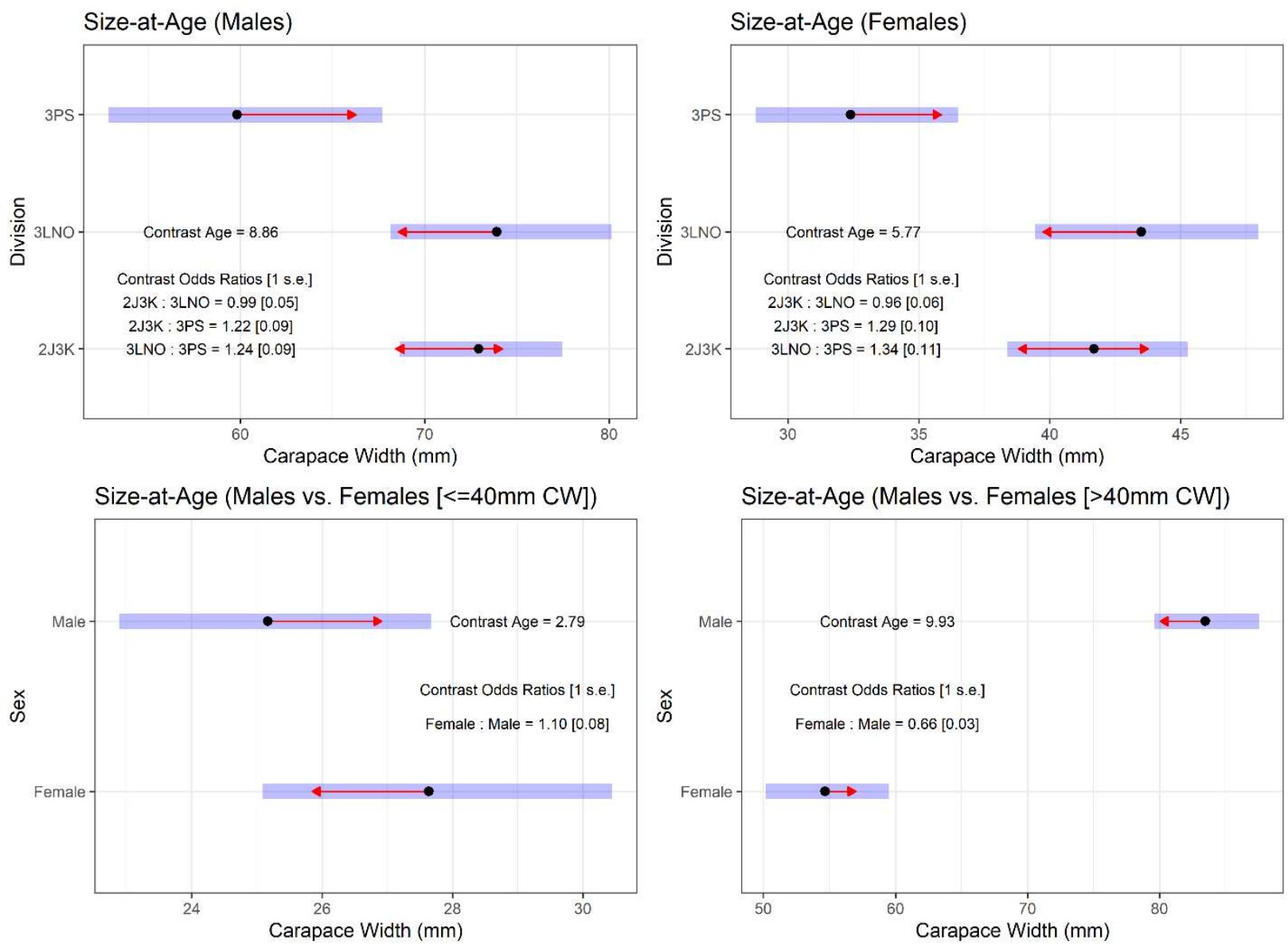

Age-at-Maturity (Males)
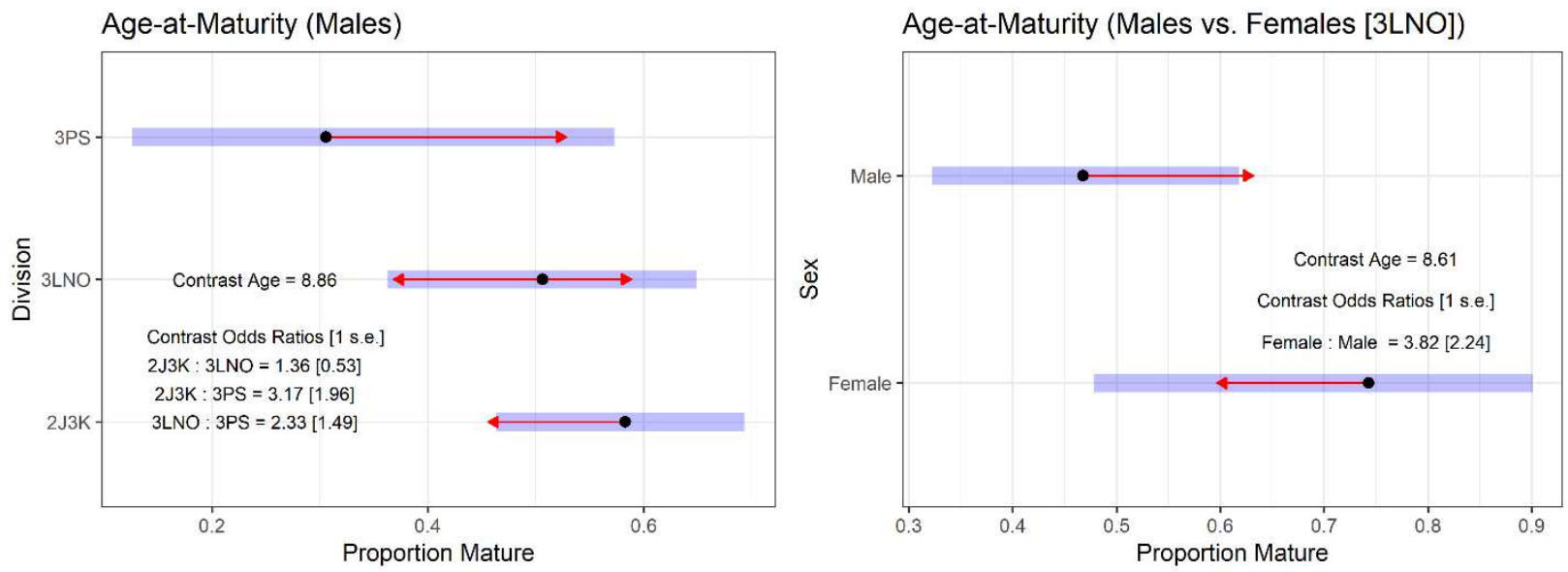

813

Figure 6. Estimated marginal means tests for pairwise comparisons of sex-specific size-at-age within each Study Division (top panels), size-at-age for sexes with Study Divisions pooled for $\leq 40 \mathrm{~mm}$ CW and $>40 \mathrm{~mm}$ CW crab groups (middle panels), age-at-maturity for males by Study Division (bottom left panel), and ageat-maturity by sex within Study Division 3LNO (bottom right panel). Point estimates of contrast ages are average ages of crab within the sample populations used in making comparisons. Blue shaded bands are 95\% confidence interval ranges for the $\mathrm{x}$-axis variables and red arrows show areas of significance among populations, with no significance in areas where arrows overlap. Odds ratios apply to the entire range of the $\mathrm{x}$-axis variables. The age-at-maturity analysis for males versus females (bottom right panel) was only done in Study Division 3LNO. 
Age-at-maturity ogives in males were characterized by a high level of variance across the entire age spectrum in all SDs, but it was nonetheless ostensible that the onset of morphometric maturity on-average occurred later in SD 3Ps than in SDs 2J3K and 3LNO (Figure 7). The GLM expectedly showed that age was a significant predictor of maturity rates in males $(\mathrm{p}<0.0001$, Table 1$)$. Overall, maturity occurred over

830 a relatively broad and largely overlapping estimated age range in the 3 SDs: 6-14 estimated age for SD 2J3K, 7-16 for SD 3LNO, and 9-14 for SD 3Ps (Figure 7). Age at 50\% maturity (mat50) in males occurred at estimated age 9 in SDs $2 \mathrm{~J} 3 \mathrm{~K}$ and 3LNO and estimated age 11 in SD 3Ps.

Despite visually apparent confirmation that SD 3Ps males on-average matured at later ages than those in SDs $2 \mathrm{~J} 3 \mathrm{~K}$ and 3Ps, the post-hoc comparisons showed no significant differences across all combinations of SDs ( $>0.05$, Table 1). The non-significance in pairwise outcomes across SDs likely reflects the high variability within the data. At 9 years of age (point estimate of 8.9 years) about $31 \%$ (proportion $=0.31$ ) of males in 3Ps were expected to be mature versus 51-58\% of males in SDs 3LNO and 2J3K, respectively, and odds ratios reflecting average likelihood of being mature at any point over the age spectrum were greater than 2 for both SD 2J3K (=3.17) and 3LNO (2.33) in comparison to SD 3Ps.

Across sexes, the comparison of model-predicted estimated ages at mat50 between males (range 8-10) and females (range 6-9) in SD 3LNO (Figure 6) suggested that males tend to undergo terminal molt at older ages than females. However, once again small sample sizes likely affected results of significance testing. Although the $\mathrm{p}=0.08$ (Table 1 ) produced by the GLM test on age between sex-specific differences in ageat-maturity in SD 3LNO was not significant at the conventional $\mathrm{p}<0.05$ level, it was suggestive of a difference in the process and was consistent with post-hoc tests which showed a higher proportion of females $(0.74)$ were expected to be mature at age 9 (point estimate age 8.6) than males $(0.47)$.

The investigation of differences in age between maturity groups for same-size crab showed mean ages of mature versus immature crab at any given size were higher in mature crab of both sexes, with overall global

852 mean differences of sex-specific pairwise comparisons being 4.6 years in females and 1.8 years in males

853 (Figure 8). The greater difference in ages between same-size mature versus immature females versus males, 854 coupled with a pattern of greatest divergence in estimated ages in the smallest males (i.e. observations of 4 855 and 6.2 years difference below $70 \mathrm{~mm} \mathrm{CW}$ in SDs $2 \mathrm{~J} 3 \mathrm{~K}$ and $3 \mathrm{LNO}$ ), are consistent with the hypothesis that 856 gastric mill bands continued to accumulate after terminal molt, particularly as overall mean differences of 
4.6 years in females and 1.8 years in males are reasonable estimates of expected post-terminal molt longevities in these unfished and fished population components.

860

861

862

863

864
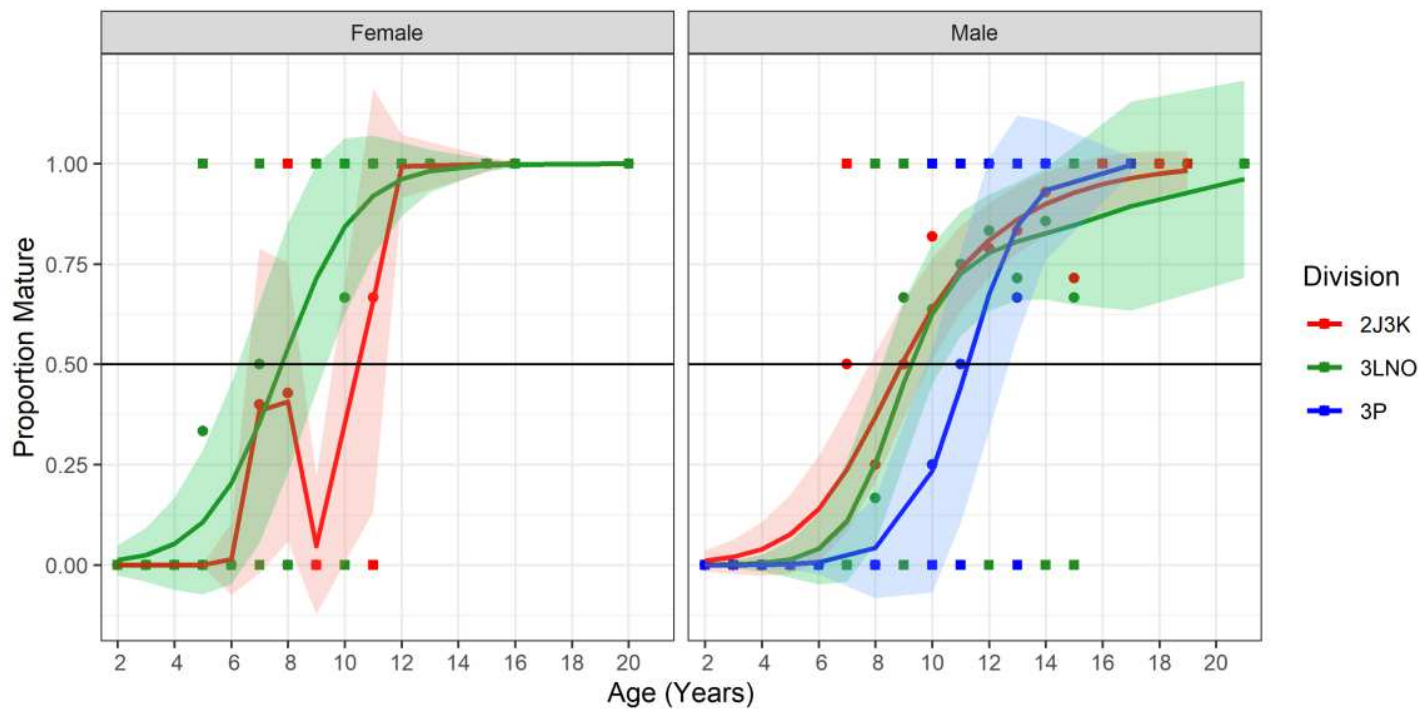

Figure 7. GAM model fits for Study Division-sex pairings of age-at-maturity data. Squares show binomial mature/immature data observations and circles show proportions mature per estimated year class. Horizontal black line shows age at 50\% maturity.
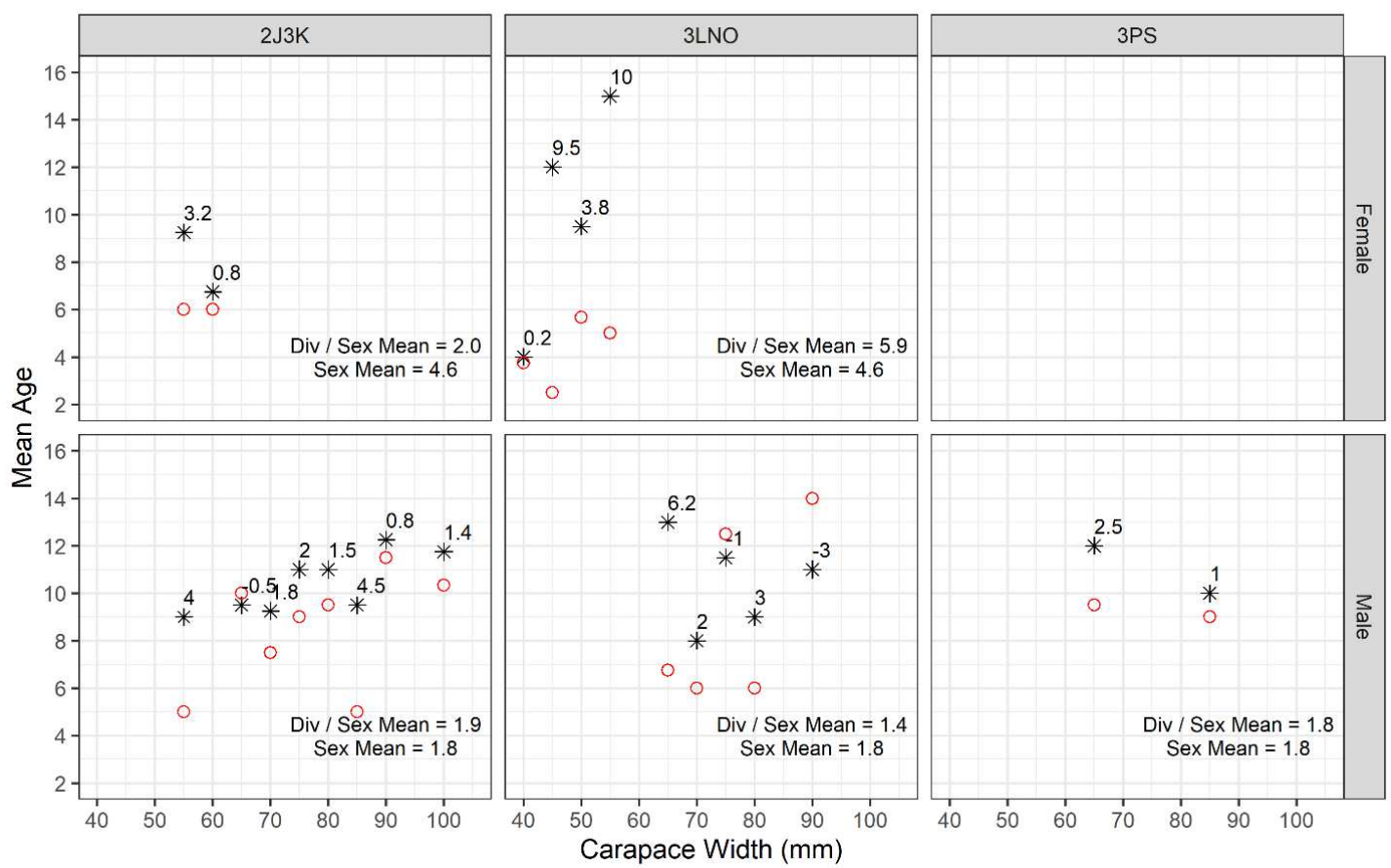

865

866

867

868

869

870
Figure 8. Mean estimated ages for mature (black stars) and immature (red open circles) snow crab for $5 \mathrm{~mm}$ CW size groupings of crab by sex and Study Division. Numeric labels indicate differences in mean age estimates (mature-immature) for each $5 \mathrm{~mm}$ carapace width paring. Div/Sex Mean refers to the average of mean differences by Study Division and sex and Sex Mean refers to the average of mean differences by sex with Study Divisions pooled. 


\subsection{Molt Frequency}

Modal size estimates for instars IV to VIII from the nGSL overall compared well with modes observed in $\leq 45 \mathrm{~mm}$ CW size frequency data from Campelen trawl surveys (1995-2020) for both sexes and in our three SDs of the NL shelf (Figure 9). This supported application of modal instar sizes for nGSL males to the aged male crab from NL (Figure 10).

Estimated average age-at-instar in immature/adolescent males revealed an intriguing pattern suggesting that instars VIII (Division 3LNO) or IX (Divisions 2J3K, 3Ps) were stages where pronounced delays in molting in NL males occurred relative to historical observations in the nGSL (Figure 10). Even with high levels of variability around the estimated age of these older crab instars in NL, a tight coupling of estimated age-atinstar occurred in all four SDs for younger instars V-VII. The divergence at instars VIII-IX resulted in NL crab being estimated at about 2 years older on-average at these and later instars than nGSL crab. For example, in all NL SDs crab at instar X were estimated to be about 8.5 years of age versus 6.5 years in the nGSL. GSL.
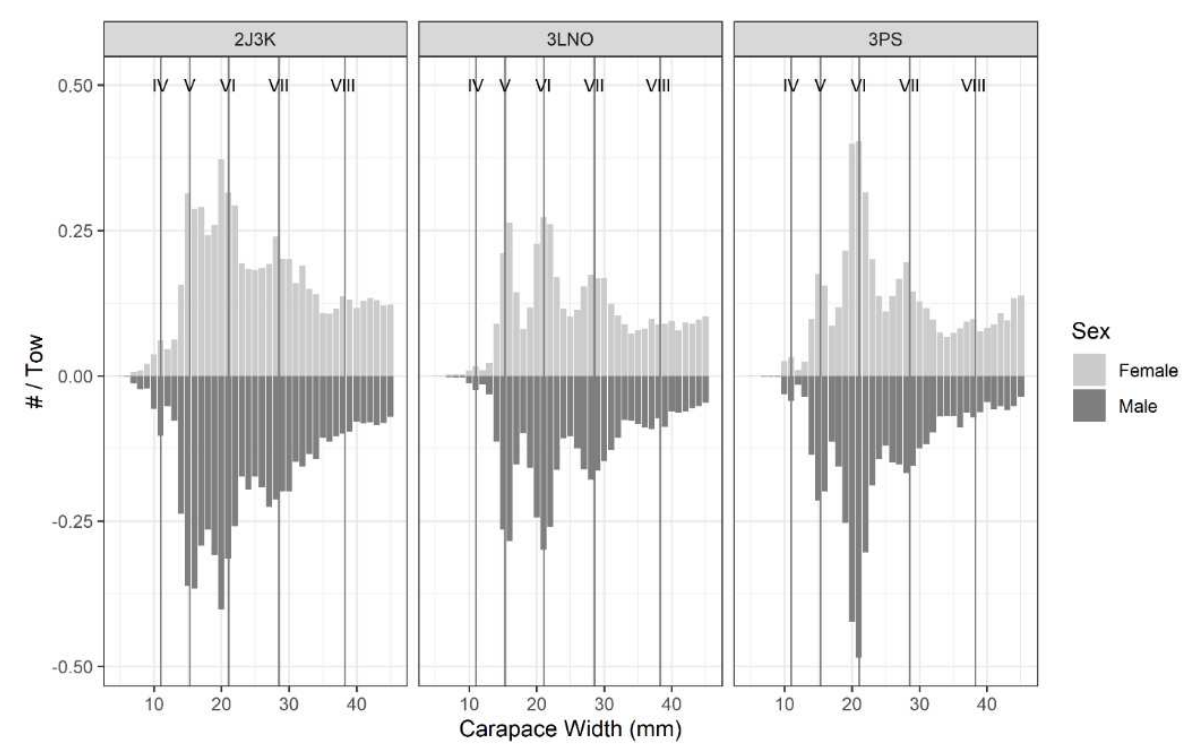

Figure 9. Size frequency distributions of female (top) and male (bottom) snow crab sampled by NL trawl surveys between 1995 and 2020 in our three study Divisions. Vertical gray lines and roman numerals show modal size-at-instar estimates from Sainte-Marie et al. 1995 for snow crab from the nGSL.

Corroborating evidence for the pronounced delays of growth into instars VIII-IX in NL males was not detected in the broader field sampling data at any point in the decade preceding 2015, when collections for the aging component of our study occurred. In most years, the overwhelming majority (i.e., $>75 \%$ in all cases, $95 \%$ on-average) of instar VIII-IX male crab in the trawl surveys were assessed to have undergone 
a regular molt, even is SD 3Ps where skip-molting rates were normally highest in any given instar and year.

897 Skip-molting incidence at these instar stages ranged from 0 to $24 \%$ (4\% on-average) in different years and 898 SDs (Figure 11).

900 The higher incidence of skip-molting in SD 3Ps males that would contribute to lower size-at-age found in 901 the aging component of this study was evident in the field data, particularly across instars IX to XIII. Skip902 molting was overall most pronounced at instars X-XI, with annual instar-specific rates of skip-molting often 903 nearing or exceeding $50 \%$ of the animals (28\% on-average). In contrast, annual instar-specific incidence of 904 skip-molting in instar IX - XIII males in SDs 2J3K and 3LNO averaged 8\% and 17\% respectively.
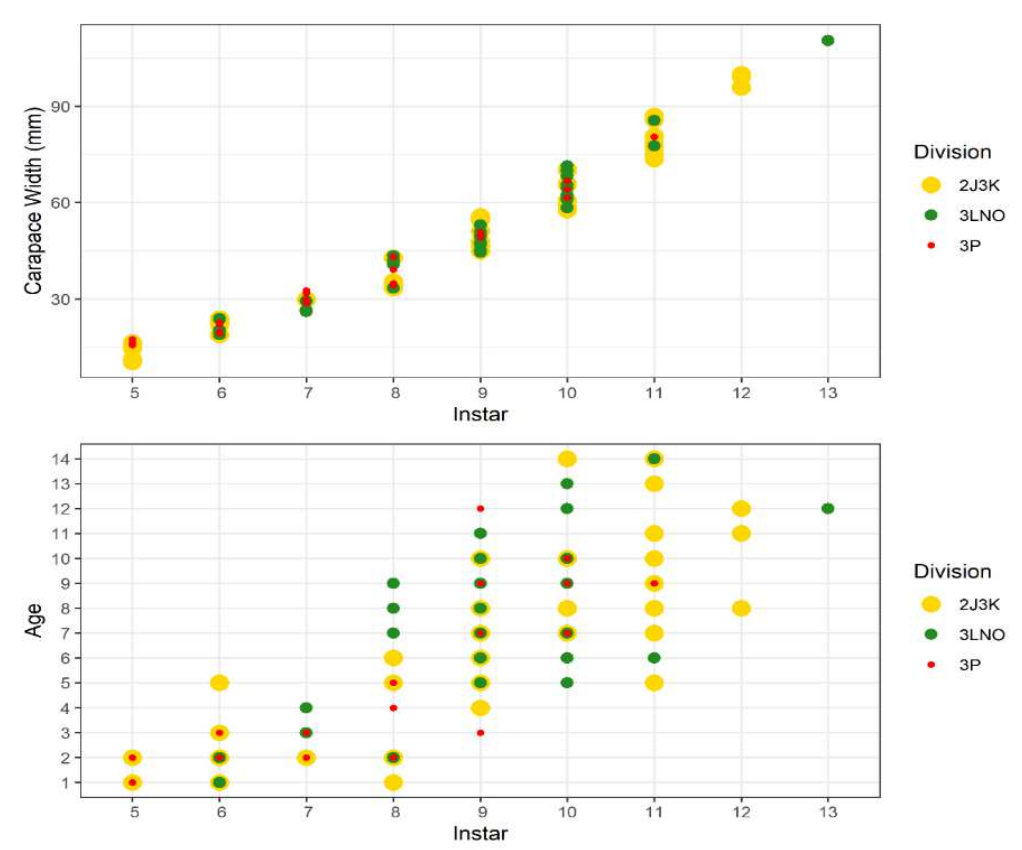

Division

2J3K

- 3 LNO

- $3 P$

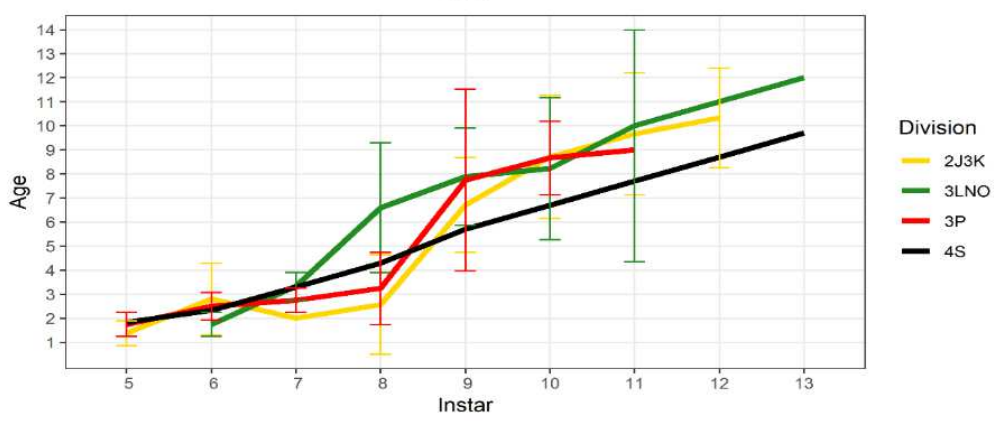

Figure 10. Top panel. Carapace width size groupings for immature/adolescent males assigned to different instar stages based on sizes reported in Sainte-Marie et al. (1995) for each NL Study Division. Middle panel. Estimated ages for individual crab assigned to particular instar grouping for each NL Study Division. Bottom panel. Mean ( \pm 1 SD) estimated age of immature/adolescent male snow crab from each 
914

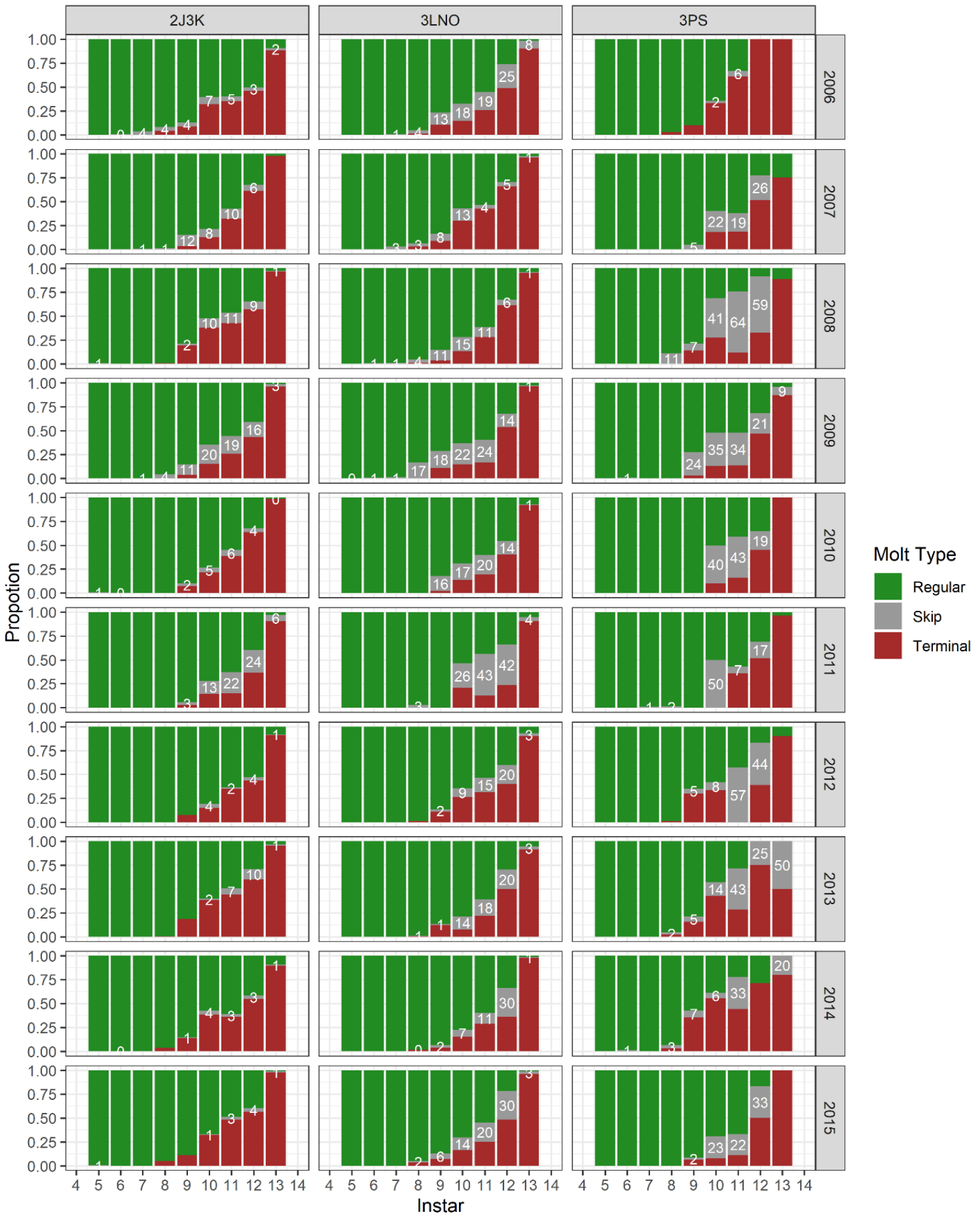

915

916

917

918

919

920

921

Figure 11. Proportion of molt type outcomes occurring during annual molting periods for immature/adolescent male crab captured in NL trawl surveys conducted in our three study Divisions from 2006-2015. Regular-molt refers to soft/new-shell adolescents, Skip-molt refers to intermediate/old-shell adolescents, and terminal-molt refers to soft/new-shell adults (see Methods for further explanations). White numbers indicate percentage of crab that skip-molted. 


\subsection{Objectives \& Expected Outcomes}

926 Results pertaining to across-sex and across-area comparisons are consistent with the hypothesis that

927 cuticular bands form in the absence of molting. The specific lines of evidence to support this key finding 928 are:

1) males in NL populations with highest skip-molting rates (SD 3Ps) had significantly lower size-atage than those from populations where skip-molting was less common (SDs 2J3K, 3LNO);

943 This suite of evidence based on differences among populations, sexes, and life stages, together with overall

944 conformity of the results with the biological literature on age and growth dynamics in snow crab, provides

945 strong support for the hypothesis that gastric mill bands accumulate independent of molting, and that gastric

946 mill age band estimations are robust against influences of molt frequency interruptions. The results also

947 indicate that chronological ages are being tracked through gastric mill age estimations. However, small

948 sample size deterrents and not fully understood observations of prolonged delays associated with male

949 progression into instar stages conforming with sexual maturation, along with potential estimation error in

950 age 1-3 crab, preclude a conclusion on whether absolute or relative ages are being consistently tracked.

951 Further uncertainties in outcomes stem from inconsistencies in the extent to which samples used for age

952 estimation reflected ambient habitat conditions across Study Divisions, which were used as the basis to 953 contrast environmental influences on age and growth dynamics. 
955 An important result of this study is that crab from the dominant areas of the NL stock range (NAFO

956 Divisions 2J3KLNOP) are estimated to be older at reaching legal-size than previously estimated, likely due

957 to higher levels of skip-molting relative to previously studied areas. This result is intuitive given that skip-

958 molting can only lead to higher ages at any given size, and until further aging analyses are done, the best

959 estimate for time to reach legal-size for male snow crab in dominant portions of the NL stock range should

960 be refined to 10-12 years of age. This estimate is on-average one to three years older than male crab in the 961 nGSL, depending on division.

962

963

964

965 A recent stream of research in validating cuticular band count methods in crustaceans has focused on 966 whether or not (or how) gastric mills are retained or regenerated upon molting, and how those processes 967 affect chronology or reliability of band accumulation patterns (i.e., Sheriden et al., 2016; Sheriden and 968 O’Connor, 2018; Becker et al., 2018; Mouser et al., 2020). Our study cannot address these important issues. 969 Notwithstanding the importance of future studies that more specifically address the mechanisms of band 970 formation, we highlight that application of blind age estimations to field data, particularly across 971 heterogeneous stock ranges, constitutes a useful ecology-based approach for continued validation of age 972 band estimation techniques.

974 We presented a comprehensive and consistent suite of evidence to either confirm or support each of our 975 literature-based expected outcomes on age and growth contrasts among spatial and demographic units. 976 Among this suite of evidence was a demonstration that gastric mill age estimations appeared to be reliably 977 tracking absolute age at some life stages in males. Specifically, the tight coupling of estimated ages of 978 immature/adolescent males in all three NL SDs with those from the nGSL over the age 4-6 range, when 979 across-population levels of molt frequency variation would be expected to be minimal, constitutes strong 980 evidence that gastric mill age band estimations were tracking chronological age during these stages 981 (discussion on issue of large sizes at ages 1-3 forthcoming). Further, the estimate of an additional 1-3 years 982 being needed by male crab from NL to reach fishery size compared to those in the nGSL is reasonable, as 983 our field data confirms that skipping of 1-3 annual molts is a realistic estimate for any given individual and 984 the most pronounced delays in age of recruitment into the fishery occurring in SD 3Ps conforms with the 985 literature.

987 Beyond males, we offer that indirect evidence from presented age and growth outcomes in females are 988 consistent in suggesting that absolute ages were being tracked by the age estimations. The literature is 
consistent in indicating females are expected to have negligible levels of skip-molting and to terminally molt over a limited number of instars, and our size-at-age and age-at-maturity data appear consistent with known reports of size-at-age and age-at-maturity in females. For example, where data were sufficient (in

992 SD 3LNO), we showed the growth curve of females to asymptote over about 55-65mm CW, with the upper 993 end of sizes along this growth curve reflecting the sizes when terminal molt occurred (a similar pattern was 994 evident in SD 2J3K, although there were limited data beyond estimated age 12). Assuming size-at-instar 995 remains similar between the sexes until instar VIII (Ito, 1970; Yamamoto et al., 2015a; Sainte-Marie et al., 996 2020), as inferred from our analysis of across-sex size-at-age in small crab, and that male size-at-instar can 997 therefore be used to infer female instar stage, the majority of females in SD 3LNO would be interpreted as 998 terminally molting within the instar IX-XI range. This is consistent with reports of strong conformity to 999 terminal molt at these instars in females (Alunno-Bruscia and Sainte-Marie, 1998; Orensanz et al., 2007).

1000 Given estimated modal sizes of $51 \mathrm{~mm}, 65 \mathrm{~mm}$, and $80 \mathrm{~mm} \mathrm{CW}$ for males at these three instars, respectively 1001 (Sainte-Marie et al., 1995), our data suggest a concentration of terminal molt in SD 3LNO females occurred 1002 at instar X. Estimated age-at-molt for instar X male crab in the nGSL was reported at 6.7 years (SainteMarie et al., 1995), a value very similar to our mat50 estimate in SD 3LNO females.

Despite evidence that absolute ages were being tracked by gastric mill age estimations in some life stages of both sexes, some of our results were inconsistent with the conclusion that gastric mill age estimations consistently tracked absolute ages at all life stages. Specifically, we highlighted an issue of potential estimation error at ages 1-3, applicable to both sexes, and potentially unrealistic delays of progression into sizes/stages associated with sexual maturity in males. Definitive reasons for both observations are unknown, but both could be the result of small sample sizes or have underlying biological reasoning (section 4.3).

1012 In-line with detractions from a supposition that gastric mill age estimations are consistently able to follow 1013 absolute ages at all life stages is the recent suggestion by Rebert et al. (2020) that band accumulation ceases 1014 in the gastric mill upon terminal molt. Our study was not designed to directly address this possibility, but 1015 our inferential analysis on mean age-at-size versus maturity status of crab suggest this was not likely the 1016 case in our specimens. We showed that mature crab at any given size were generally older at age than 1017 immature crab, in both sexes in all SDs where data sufficed for analysis, and that overall differences of 4.6 1018 and 1.8 years, for females and males respectively, are reasonably consistent with what would be expected 1019 as a typical post-terminal molt longevity in the absence (females) and presence (males) of fishing. In 1020 extension of our interpretation that gastric mill bands accumulate during skip-molts, we find that that weight 1021 of evidence presented in our study suggests that they do also accrue after terminal molt. Accordingly, this 1022 more broadly leads to our supposition that gastric mill bands are following some chronological pattern over 
1023 the entire course of post-settlement ontogeny. Nonetheless, we note that Rebert et al. (2020) were not

1024 definitive in their suggestions that bands do stop accumulating after terminal molt and highlight that we

1025 cannot be definitive in refuting them. It is important to note that that neither study was designed to directly

1026 estimate ages from known aged crab and in-turn directly answer the specific question of whether or not

1027 bands accrue following terminal molt, with both relying on indirect proxy methods and interpretations to

1028 address the issue. Accordingly, we recognize this remains an unresolved important research question that

1029 may best be addressed by a laboratory study housing pre- and post-terminal molt crab of known ages.

\subsection{Snow Crab Growth Dynamics}

1032

1033 The possibility of systematic estimation error for ages 1-3 crab is associated with a far greater degree of 1034 variance associated with age estimations in NL versus nGSL males as detailed in Section 3.2.2. This reflects 1035 small sample size limitations in the NL data and highlights the need to focus on sample-level means as 1036 opposed to individual age estimations when interpreting ages. There is no doubt observation error 1037 associated with the age estimation methods, as it can be challenging to prepare quality images and reader 1038 interpretations can vary. However, it is not clear if greater sample sizes would change the outcome of the 1039 analysis on aging these young crab, particularly if there is an underlying intrinsic or an extrinsic factors that 1040 lead to faster growth rates in the NL samples versus those form the nGSL. The high variance was not 1041 attributable to one or two observations, but rather a consistently high level of spread of sizes at these young 1042 estimated ages across SDs and sexes (see Figure 4).

1044 To address the possibility that some intrinsic attribute may contribute to underestimation of ages in young 1045 crab, among other unknown possibilities, we highlight that these are the stages during which crab molt 1046 more than annually. Accordingly, it is plausible that the band accumulation process may be most 1047 inconsistent during these years. However, if this were the case we would expect to see underestimation over 1048 the remainder of the age range rather than a convergence with the estimated size-at-age from the nGSL in 1049 the analysis on immature/adolescent males. The convergence in estimated size-at-age with the nGSL 1050 'control' population after age 3 suggests that the estimated ages were 'real', and that the 1-3 year old NL 1051 crab were in fact substantially larger than same-age individuals in nGSL population, which suggests that 1052 the former underwent more rapid molting than the latter. We undertook an exploratory post-hoc analysis to 1053 address this possibility.

1055 Based on inter-molt period versus temperature data from lab studies in Yamamoto et al. (2015a) and Sainte1056 Marie et al. (2021), we estimated that for a crab to reach instar VII by age 2 it would have needed to 
experience ambient temperatures of about $2.5^{\circ} \mathrm{C}$ over the preceding instars if tank-based results held in wild populations. An examination of size versus temperature data from the trawl surveys (Figure 12) reveals this is in fact a possibility, particularly in SDs $2 \mathrm{~J} 3 \mathrm{~K}$ and $3 \mathrm{LNO}$ (Figure 12). It should be cautioned that the survey trawl is known to be inefficient at capturing crab below about 12-15mm CW (i.e. Baker et al., 2021), and that these early-life instars are not typically considered in distributional analyses of NL snow crab demographics (i.e. Dawe and Colbourne, 2002; Mullowney et al., 2018). Nevertheless, where temperature

1063 data were available on crab corresponding to instar sizes VII or less during the 2012-2015 years, which 1064 represent the temperatures our 1-3 year old crab would have experienced, it was apparent in several 1065 instances that mean capture depths were near $2.5^{\circ} \mathrm{C}$. Broadly, the early-1990s years during which the nGSL samples were taken were among the coldest on record for the Atlantic Canada marine shelf ecosystem while the more recent period during which the NL samples were taken has been much warmer (Cyr and Galbraith, 2021). We do not purport this to be a full explanation for the higher age estimates of 1-3 year old crab in NL, but we highlight that it suggests the aging method was reliably detecting unexpectedly large size-atage in these young crab.

1072

1073

1074

1075

1076

1077
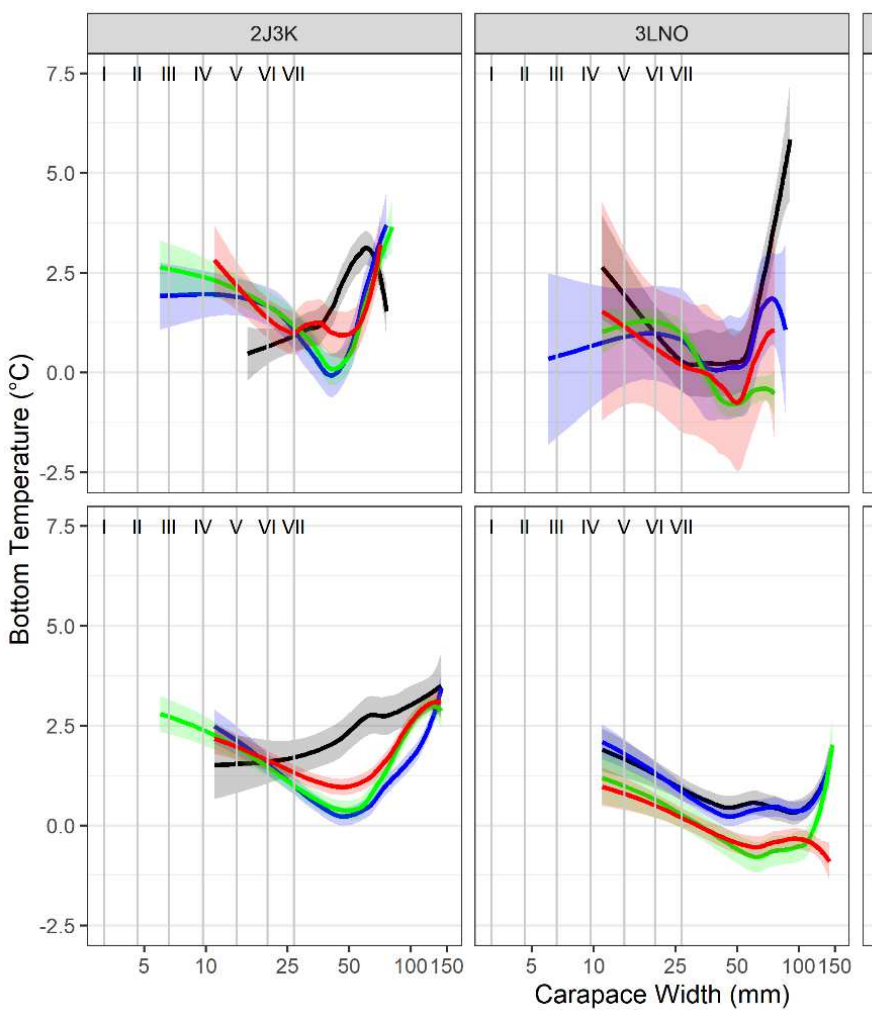
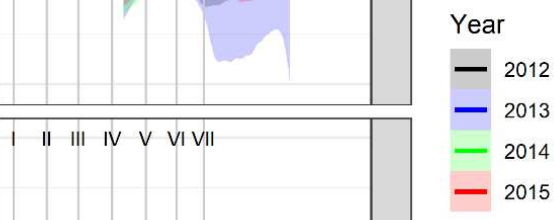

Figure 12. Loess regression models fit to weighted-average bottom temperatures for capture locations for $5 \mathrm{~mm}$ carapace width bin groups of crab in trawl surveys in the three NL Study Divisions during 20122015 , by sex. Shaded bands show $95 \%$ confidence intervals around model fits. X-axis plotted in logarithmic scale. Vertical gray lines and roman numerals show modal size-at-instar estimates for instar IIV from Sainte-Marie et al. 1995 for snow crab from the nGSL. 
1078 Among the most intriguing observations in this study was an apparent delay in progression of male snow

1079 crab into instars VIII and IX in NL populations in comparison to nGSL crab. The growth delays during this

1080 stage account for the dampening of the growth curves for NL adolescent males after age 6. Ultimately,

1081 pronounced delays during these stages explained much of the one to three year difference in age at legal-

1082 size between NL and nGSL male crab. This analysis was undoubtedly affected by small sample size, as

1083 evident by high variance around age-at-instar means (see Figure 10), which affect interpretation of the

1084 magnitude of the time delay. For example, a lag of up to 4-5 years from one instar stage to the next within

1085 any given SD is simply not deemed as biologically plausible, but the overall pattern of an average delay of

1086 about two years in progression occurring over the instar VII-X period within any given SD is plausible.

1087 Notwithstanding uncertainty in interpreting the magnitude of growth delays during this period, the timing

1088 of the life stages where it occurs warrants further elaboration.

1090 Instars VIII and IX are the stages at which sexual maturity (puberty/regular molt) commonly occurs in male snow crab (Kon and Honma, 1978; Sainte-Marie et al., 1995). Accordingly, it is conceivable that energy budgeting changes occur in the crab at this point, as occurs in the puberty/terminal molt of females (AlunnoBruscia and Sainte-Marie, 1998; Dawe et al., 2012), which provides a potential biological explanation for these prolonged inter-molt periods. However, to continue the logic of energy allocation differences among populations, it is also known that this is the life stage at which the onset of extensive down-slope ontogenetic movements begin, or are occurring, in snow crab males in NL (Mullowney et al., 2018), and that these movements occur over much smaller spatial scales in the nGSL (Lovrich et al., 1995). It is quite plausible that higher levels of competing demands on energy allocation lead to reduced growth rates via relatively high levels of skip-molting during this life stage in NL males.

Although the timing of the most pronounced skip-molt delay period in NL males relative to the nGSL aligns

1102 with several important life history processes that may partially explain it, this is not the only stage(s) at 1103 which skip-molting growth delays occur. Indeed, the long-term field survey data from NL showed that 1104 highest incidences of visually-determined rates of skip-molting often occurred later, at instars X-XII. We 1105 speculate that, in-line with imprecision in using shell condition staging as a proxy for post-molt time 1106 (Fonseca et al., 2008), there is potential for systematic bias in the subjective visual shell condition staging 1107 method, with progressively larger crab more routinely assessed at a higher shell deterioration stage than 1108 small crab. This suggestion is partially based on a sampling artefact pertaining to small crab in the survey 1109 data that became evident during this study. To elaborate, it is likely that skip-molting delays growth in NL 1110 crab prior to instars VIII-IX, but such delays go undetected in the current monitoring program. Skip-molting 1111 almost certainly occurs at instars earlier than VIII (Yamamoto et al., 2015a; Sainte-Marie et al., 2021) but 
1112 shell conditions in these young instars would not routinely advance beyond the "new-shell" category, 1113 because inter-molt periods are less than a year (Yamamoto et al., 2015a; Sainte-Marie et al., 2020).

1114 Consequently, skip-molters at young instars go undetected in the trawl-survey data using the criteria that

1115 they are immature/adolescent males with a shell condition advanced beyond new-shell. Indeed, the post-

1116 hoc analysis on recent thermal distribution of crab (Figure 12) revealed that in some SDs and years smallest

1117 crab were captured in waters warm enough to promote rapid molting, but it also revealed that in some SDs

1118 and years, particularly in SD 3Ps, these earliest instar crab would be captured in cold temperatures (i.e. 0-

$11191^{\circ} \mathrm{C}$ ) sufficient to induce common incidence of skip-molting.

\subsection{Uncertainties \& Future Work}

Two of the major sources of uncertainties inherent in our analyses are small sample sizes and the degree of 1124 representativeness of the samples used in the aging study in reflecting ambient habitat conditions. These 1125 issues are not mutually exclusive, as increased samples sizes would have likely been associated with 1126 broader coverage of sample locations within the SDs. Nonetheless, the consistency with which the 1127 outcomes of analyses matched literature-based expectations concerning age and growth dynamics across 1128 SDs, sexes, and life history stages suggests these issues did not prevent the ability to address the central research question of whether or not gastric mill bands are formed when crab do not molt. For example, it was fully expected that SD 3Ps crab would be overall smaller at age than those in the other SDs and the aging data were able to detect this.

1133 The issue of representativeness of the 'snapshot' samples used in the aging study extends beyond the time 1134 and locations where collections occurred into long-term spatial contraction of the resource associated with 1135 a large decrease in stock productivity (Mullowney et al., 2020; Baker et al., 2021). This issue could only 1136 have been addressed through a dedicated long-term sampling program, which would have enabled 1137 environmental influences on age and growth dynamics of snow crab to be monitored in real-time. We 1138 recommend such an approach for future ecological-based studies examining age and growth dynamics in 1139 snow crab populations, and crustaceans in general. In this regard, it was somewhat surprising that the age 1140 and growth dynamics of SDs $2 \mathrm{~J} 3 \mathrm{~K}$ and $3 \mathrm{LNO}$ crab matched so closely. The crab in these SDs do not 1141 consistently occupy matching habitats, with those is SD 3LNO being typically found in shallower and 1142 colder waters than those is SD 2J3K (Mullowney et al. 2018). In this respect, future work on the relative 1143 influences of population density versus physical environmental attributes on age and growth dynamics 1144 would be beneficial. 
1146 Despite its shortcomings, this study is comprehensive in its comparative analyses and breadth of novel age-

1147 based outcomes that are consistent with field data and literature on snow crab growth dynamics. The basis

1148 to conclude that bands in the gastric mill form independent of molting, and that the aging method is able to

1149 detect this, is strong. The study also presents compelling evidence that absolute ages are being tracked, at

1150 least during some life stages. To enable a firmer conclusion on whether or not absolute ages are being

1151 reliably tracked over all stages of life, we suggest that the aging of frequently molting young crab ( ages

1152 1-3) from warm and cold water wild populations needs to occur, better precision on the extent to which

1153 skip-molt delays occur concomitant with male sexual maturity needs to be developed, and verification of

1154 gastric mill band accumulation post-terminal should be done. Finally, to give broader credence to the

1155 crustacean aging methods in general, including the ability to conclude that absolute ages are being tracked

1156 during all life stages, the underlying mechanisms controlling cuticular band formation needs to be 1157 understood [13530].

\subsection{Acknowledgments}

1160 The aging study portion of this analysis formed the basis of a Master's program for author N.O. We are 1161 grateful to the Government of Newfoundland and Labrador for helping financially support the project via 1162 a contribution from the Department of Fisheries and Aquaculture. We hope this work can contribute to 1163 improved science and management for this most valuable fisheries resource in this Province. A NSERC 1164 study grant to R.R. also helped support this project. Dr. Mikio Moriyasu is thanked for his time and expertise 1165 in serving as a reviewer for the Master's defense of N.O. We thank the Technicians in the Science Branch 1166 of DFO in St. John's, Newfoundland \& Labrador, for providing the field samples used in the aging study 1167 as well as their on-going work in compiling the impressive data repository from trawl surveys used in this 1168 analysis. This paper benefitted greatly from internal reviews by Dr. Rick Rideout and Dr. Bernard Sainte1169 Marie prior to submission. Refinements to the paper structure and continued education on many details of 1170 the complex life history attributes of snow crab are credited to them.

\section{$1173 \quad 5.0$ Declarations}

1174 Funding: The Government of Newfoundland and Labrador (Department of Fisheries and Aquaculture) 1175 provided a study grant to student N. O'Connell and the project received funding from an NSERC Discovery 1176 grant to author RR at the University of New Brunswick (RGPIN-2017-04616). Conflicts of Interest: None. 1177 Availability of data and material: All data used in this study and pre-processing details are available upon 1178 request to DM. The aging specimen data are a small dataset and require minimal pre-processing information 
1179 to use while the trawl survey data from NL are a large dataset and require more pre-processing information

1180 prior to use. It is anticipated the trawl survey data will be freely available online in forthcoming years. Code

1181 availability: The code used for all analyses was written in $\mathrm{R}$ version 4.0.2 and is available upon request to

1182 DM. Authors' contributions: Conceptualization [Rémy Rochette, Raouf Kilada]; Methodology [Raouf

1183 Kilada, Rémy Rochette, Nicole O’Connell, Darrell Mullowney]; Formal analysis and investigation [Darrell

1184 Mullowney]; Writing - original draft preparation [Darrell Mullowney]; Writing - review and editing

1185 [Nicole O’Connell, Rémy Rochette, Raouf Kilada]; Funding acquisition [Rémy Rochette, Raouf Kilada,

1186 Darrell Mullowney]; Supervision [Rémy Rochette, Raouf Kilada]. Animal Care: All crab specimens were

1187 collected, euthanized, and examined in accordance with animal care ethics standards of Fisheries and

1188 Oceans Canada and the University of New Brunswick.

References

1191 Alunno-Bruscia, M, Sainte-Marie, B (1998) Abdomen allometry, ovary development, and growth of 1192 female snow crab, Chionoecetes opilio (Brachyura: Majidae), in the northwestern Gulf of St Lawrence. 1193 Can J Fish Aquat Sci 55:459-477. https://doi.org/10.1139/f97-241

Baker K, Mullowney D, Pedersen E, Coffey, W, Cyr, F, Belanger, D (2021) An Assessment of Newfoundland and Labrador Snow Crab (Chionoecetes opilio) in 2018. Can Sci Advis Sec Res Doc $2021 / 028$.

Becker C, Dick JTA, Cunningham EM, Schmitt C, Sigwart JD (2018) The crustacean cuticle does not record chronological age: new evidence from the gastric mill ossicles. Arth Str Dev 47:498-512. https://doi.org/10.1016/j.asd.2018.07.002

Burmeister AD, Sainte-Marie B (2010) Pattern and causes of a temperature-dependent gradient of size at terminal moult in snow crab (Chionoecetes opilio) along West Greenland. Pol Biol 33:775-788.

Catlin N (2020) Age validation, size-at-age, size-at-maturity, and ate-at-maturity in snow crab (Chionoecetes opilio) from different thermal regimes in Newfoundland, University of New Brunswick

Campana SE (2001) Accuracy, precision and quality control in age determination, including a review of the use and abuse of age validation methods. J Fish Biol 59:197-242. https://doi.org/10.1111/j.10958649.2001.tb00127.x

Chabot D, Sainte-Marie B, Briand K, Hanson, J (2008) Atlantic cod and snow crab predator-prey size relationship in the Gulf of St. Lawrence, Canada. Mar Ecol Prog Ser 363:227-240. https://doi.org/10.3354/meps07384

Claxton WT, Govind CK, Elner RW (1994) Chela function, morphometric maturity, and mating embrace in male snow crab, Chionoecetes opilio. Can J Fish Aquat Sci 51:1110-1118. https://doi.org/10.1139/f94110

1220 Colbourne EG, Mertz G (1998) Spatial and temporal variability of ocean temperature over the Labrador 1221 Shelf. Atm-Ocn 36:299-317. https://doi.org/10.1080/07055900.1998.9649615 
1222

1223

1224

1225

1226

1227

1228

1229

1230

1231

1232

1233

1234

1235

1236

1237

1238

1239

1240

1241

1242

1243

1244

1245

1246

1247

1248

1249

1250

1251

1252

1253

1254

1255

1256

1257

1258

1259

1260

1261

1262

1263

1264

1265

1266

1267

1268

1269

Comeau M, Robichaud G, Starr M, Therriault J-C, Conan G (1998) Mating of snow crab (Chionoecetes opilio, O. Fabricius 1788) (Decapoda, Majidae) in the fjord of Bonne Bay, Newfoundland. Crust 71:925941.

Conan GY, Comeau M (1986) Functional maturity and terminal molt of male snow crab. Can J Fish Aquat Sci 43:1710-1719. https://doi.org/10.1139/f86-214

Cyr F, Galbraith PS (2021) A climate index for the Newfoundland and Labrador shelf. Earth Syst Sci Data 13:1807-1828. https://doi.org/10.5194/essd-13-1807-2021

Dawe EG, Colbourne EB (2002) Distribution and demography of snow crab (Chionoecetes opilio) males on the Newfoundland and Labrador shelf. In: Crab in Cold Water Regions: Biology, Management, and Economics, Alaska Sea Grant College Program AK-SG-02-01, Anchorage, pp 577-594.

Dawe EG, Mullowney DR, Moriyasu M, Wade E (2012) Effects of temperature on size-at-terminal molt and molting frequency in snow crab Chionoecetes opilio from two Canadian Atlantic ecosystems. Mar Ecol Prog Ser 469:279-296.

DFO (2021) Assessment of Newfoundland and Labrador (Divisions 2HJ3KLNOP4R) snow crab. Can Sci Advis Sec Sci Advis Rep 2021/009.

Elner RW, Beninger PG (1995) Multiple reproductive strategies in snow crab, Chionoecetes opilio: Phyiological pathways and behavioral plasticity. J Exp Mar Biol Ecol 193:93-112. https://doi.org/10.1016/0022-0981(95)00112-3

Ernst B, Orensanz, JM(Lobo), Armstrong DA (2005) Spatial dynamics of female snow crab (Chionoecetes opilio) in the eastern Bering Sea. Can J Fish Aquat Sci 62: 250-268.

Fonseca DB, Sainte-Marie B, Hazel F (2008) Longevity and change in shell condition of adult male snow crab inferred from dactyl wear and mark-recapture data. Trans Am Fish Soc 137:1029-1043. https://doi.org/10.1577/T07-079.1

Gnanalingam G, Butler IV MJ, Metthews TR, Hutchinson E, Kilada R (2018) Directly Ageing the Caribbean Spiny Lobster, Panulirus argus with Validated Band Counts from Gastric Mill Ossicles. ICES J Mar Sci 76:442-451. https://doi.org/10.1093/icesjms/fsy177

Hartnoll RG (2001) Growth in Crustacea - twenty years on. Hydrobiologia 449:111-122.

Hébert M, Benhalima K, Miron G, Moriyasu M (2002) Moulting and growth of male snow crab, Chionoecetes opilio (O. Fabricius, 1788) (Decapoda, Majidae), in the southern Gulf of St. Lawrence. Crustaceana 75: 671-702.

Hébert M, Wade E, DeGrâce P, Moriyasu M (2017) The 2016 assessment of the snow crab (Chionoecetes opilio) stock in the southern Gulf of St. Lawrence (Areas 12, 19, 12E and 12F). Can Sci Advis Sec Res Doc 2017/049.

Hines AH (1989) Geographic variation in size at maturity in brachyuran crab. Bull Mar Sci 45: 356-368.

Hoenig JM, Dawe EG, O'Keefe PG (1994) Molt indicators and growth per molt for male snow crab (Chionoecetes opilio). J Crust Biol 14: 273-279. https://doi.org/10.1163/193724094X00263 
Hunstsberger CJ, Kilada R, Ambrose Jr. WG, Wahle RA (2020) Age-at-size relationships of the American lobster (Homarus americanus) from three contrasting thermal regimes using gastic mill band counts as a direct aging technique. Can J Fish Aquat Sci 77:1733-1740. https://doi.org/10.1139/cjfas2020-0018

Ito K (1970) Ecological studies on the edible crab, Chionoecetes opilio O. Fabricius in the Japan Sea. Age and growth as estimated on the basis of the seasonal changes in the carapace width frequencies and the carapace hardness. Bull Jpn Sea Reg Fish Res Lab 22: 81-116 (Fish Res Board Can Trans Ser 1512).

Kilada R, Sainte-Marie B, Rochette R, Davis N, Vanier C, Campana S (2012) Direct determination of age in shrimps, crab, and lobsters. Can J Fish Aquat Sci 69:1728-1733. https://doi.org/10.1139/cjfas-20120254

Kilada R, Agnalt A-L, Arboe NH, Bjarnason S, Burmeister A, Farestveit E, Gíslason ÓS, Guðlaugsdóttir A, Guðmundsdóttir D, Jónas Páll Jónasson JP, Jónsdóttir IG, Kvalsund M, Sheridan M, Stansbury D, Søvik G (2017) Feasibility of using growth band counts in age determination of four crustacean species in the north Atlantic. J Crust Biol 35:499-503. https://doi.org/10.1163/1937240X-00002353

Kilada R, Driscoll JG (2017) Age Determination in Crustaceans: A Review. Hydrobiologia 799:21-36. https://doi.org/10.1007/s10750-017-3233-0

Kilada R, Webb JB, McNeel KW, Slater LM, Smith Q, Ferguson J (2017) Preliminary assessment of direct age determination for 3 commercially important crustaceans from Alaska. Fish Bull 115:42-49.

Kolts JM, Lovvorn JR, North CA, Janout MA (2015) Oceanographic and demographic mechanisms affecting population structure of snow crab in the northern Bering Sea. Mar Ecol Prog Ser 518:193-208. https://doi.org/10.3354/meps11042

Kon T, Honma Y (1978) Studies on gonad maturity in some marine invertebrates IV. Seasonal changes in testes of the Tanner crab. Bull Jpn Soc Sci Fish 36:1028-1033 (Fish Res Board Can Trans Ser 1783).

Kon T (1980) Studies on the life history of the Zuwai crab, Chiomecetes opilio (0. Fabricius). Spec Publ Sado Mar Biol Stn Niigata Univ Ser 2 (Can Trans Fish Aquat Sci 5634).

Leland JC, Coughran J, Bucher DJ (2011) A preliminary investigation into the potential value of gastric mills for ageing crustaceans. In: Asakura A (ed) New Frontiers in Crustacean Biology. Tokyo, pp57-68. https://doi.org/10.1163/ej.9789004174252.i-354.52

Leland JC, Bucher DJ, Coughran J (2015) Direct age determination of a subtropical freshwater crayfish (Redclaw, Cherax quadricarinatus) using ossicular growth marks. PLOS ONE. https://doi.org 10.1371/journal.pone.0134966 73:1712-1726.

Miller RJ, Watson J (1976) Growth per molt and limb regeneration in the spider crab, Chionoecetes opilio. J Fish Res Board Can 33:1644-1649. https://doi.org/10.1139/f76-208 

mating of snow crab (Chionsecetes opilio) in relation to fumctional and morphometric maturity. ICES C.M. B987/K:21.

1322 Mouser JB, Glover J, Brewer SK (2020) Gastric mill age estimates for ringed crayfish Faxonius neglectus 1323 neglectus (Faxon) and the influence of temperature on band formation. Fresh Cray 25:59-67.

1324 Mullowney D, Morris C, Dawe E, Zagorsky I, Goryanina S (2018) Dynamics of snow crab (Chionoecetes opilio) movement and migration along the Newfoundland and Labrador and Eastern Barents Sea continental shelves. Rev Fish Biol Fish 28:435-459. https://doi.org/10.1007/s11160-017-9513-y

Mullowney DRJ, Baker KD, Zabihi-Seissan S, Morris C (2020) Biological perspectives on complexities of fisheries co-management: A case study of Newfoundland and Labrador snow crab. Fish Res 232:105728. https://doi.org/10.1016/j.fishres.2020.105728

1330 Mullowney DRJ, Baker KD (2021) Size-at-maturity shift in a male-only fishery: factors affecting molt1331 533. https://doi.org/10.1093/icesjms/fsaa164

Murphy JT (2019) Patterns and implications of skip-molting for the Eastern Bering Sea snow and Tanner crab (Chionoecetes opilio and C. bairdi). Fish Res 210: 63-70.

https://doi.org/10.1016/j.fishres.2018.10.006

Murphy JT (2021) Temporal and spatial variability in size-at-maturity for the eastern Bering Sea snow and Tanner crab (Chionoecetes opilio and C. bairdi). Fish Res 234:105761.

https://doi.org/10.1016/j.fishres.2020.105761

Nichol DG, Somerton DA (2015) Seasonal migrations of morphometrically mature male snow crab ((Chionoecetes opilio) in the eastern Bering Sea in relation to mating dynamics. Fish Bull 113:313-326.

1344 Orensanz JM (Lobo), Ernst B, Armstrong DA (2007) Variation of Female Size and Stage at Maturity in 1345 Snow Crab (Chionoecetes Opilio) (Brachyura: Majidae) from the Eastern Bering Sea. J Crust Biol 1346 27:576-591. https://doi.org/10.1651/S-2790.1

1347 Parada C, Armstrong DA, Ernst B, Hinckley S, Orensanz JM (2010) Spatial dynamics of snow crab (Chionoecetes opilio) in the Eastern Bering Sea - putting together the pieces of the puzzle. Bull Mar Sci 86:413-437. Sci 65:425-436. https://doi.org/10.1139/f07-163

Piper DJW (1991) Seabed geology of the Canadian eastern continental shelf. Con Shelf Res 11:10131035. https://doi.org/10.1016/0278-4343(91)90089-O

R Core Team. 2020. R: A language and environment for statistical computing. R Foundation for Statistical Computing, Vienna Austria.

1361

Rebert AL, Kruse GH, Webb JB, Tamone SL, Oxman D, McNeel KW (2020) Evaluation of a direct age estimation method for terminally molted male snow crab Chionoecetes opilio 
1362

1363

1364

1365

1366

1367

1368

1369

1370

1371

1372

1373

1374

1375

1376

1377

1378

1379

1380

1381

1382

1383

1384

1385

1386

1387

1388

1389

1390

1391

1392

1393

1394

1395

1396

1397

1398

1399

1400

1401

1402

1403

1404

1405

1406

1407

1408

1409

1410

(Fabricius 1788) (Decapoda: Brachyura: Oregoniidae). J Crust Biol 40:549-555. https://doi.org/10.1093/jcbiol/ruaa043

Robichaud DA, Bailey RFJ, Elner RW (1989) Growth and distribution of snow crab, Chionoecetes opilio, in the southeastern Gulf of St. Lawrence. J Shell Res 8:13-23.

Lenth RV (2021) emmeans: Estimated Marginal Means, aka Least-Squares Means. R package version 1.6.1. https://CRAN.R-project.org/package=emmeans

Sainte-Marie B, Hazel F (1992) Moulting and mating of Snow Crab, Chionoecetes opilio (O. Fabricius), in Shallow Waters of the Northwestern Gulf of Saint Lawrence. Can J Fish Aquat Sci 49:1282-1293. https://doi.org/10.1139/f92-144

Sainte-Marie B, Raymond S, Brêthes J-C (1995) Growth and maturation of the benthic stages of male snow crab, Chionoecetes opilio (Brachyura: Majidae). Can J Fish Aquat Sci 52:903-924. https://doi.org/10.1139/f95-091

Sainte-Marie B, Sévigny J, Smith BD, Lovrich GA (1996) Recruitment variability in snow crab (Chionoecetes opilio): pattern, possible causes, and implications for fishery management. In: Crab in Cold Water Regions: Biology, Management, and Economics, Alaska Sea Grant College Program AK-SG-9602, Anchorage, pp 451-478.

Sainte-Marie B, Sévigny J-M, Gauthier Y (1997) Laboratory behavior of adolescent and adult males of the snow crab Chionoecetes opilio mated noncompetitively and competitively with primiparous females (Brachyura: Majidae). Can J Fish Aquat Sci 54:239-248.

Sainte-Marie B, Ouellet J-F, Dionne H (2021) Direction, ontogeny, and mechanism of the temperaturesize rule operating in a large marine crab, Chionoecetes opilio. ICES J. Mar. Sci. 78:557-574. https://doi.org/10.1093/icesjms/fsaa163.

Searle SR, Speed FM, Milliken GA (1980) Population marginal means in the linear model: An alternative to least squares means. The Am Stat 34:216-221

Sheridan M, O'Connor I, Henderson AC (2016) Investigating the Effect of Molting on Gastric Mill Structure in Norway Lobster (Nephrops norvegicus) and its Potential as a Direct Ageing Tool. J Exp Mar Biol Ecol 484:16-22. https://doi.org/10.1016/j.jembe.2016.08.005

Sheridan M, O'Connor I (2018) Evidence of complete gastric mill ossicle loss at ecdysis in the European green crab Carcinus maenas (Linnaeus, 1758) (Decapoda: Brachyura: Carcinidae). J Crust Biol 38:435442. https://doi.org/10.1093/jcbiol/ruy045

Taylor DM, Hoenig JM (1990) Growth per molt of male snow crab Chionoecetes opilio from Conception and Bonavista Bays, Newfoundland. Fish Bull US 8:753-760.

Taylor DM, O’Keefe PG, Fitzpatrick C (1994) A snow crab, Chionoecetes opilio (Decapoda, Majidae), fishery collapse in Newfoundland. Fish Bull 92:412-419.

Vogt G (2012) Ageing and longevity in the Decapoda (Crustacea): a review. Zoologischer Anzeiger 251:1-25. https://doi.org/10.1016/j.jcz.2011.05.003 
1411 Yamamoto T, Yamada T, Kinoshita T, Ueda Y, Fujimoto H, Yamasaki A, Hamasaki K (2015a) Effects of 1412 temperature on growth of juvenile snow crab, Chionoecetes opilio, in the laboratory. J Crust Biol 35:1401413 148. https://doi.org/10.1163/1937240X-00002309

1414

Yamamoto T, Yamada T, Kinoshita T, Ueda Y, Fujimoto H, Yamasaki A, Hamasaki K (2015b) Growth and moulting of wild-born immature snow crab, Chionoecetes opilio (Fabricius,

1419 Yamamoto T, Yamada T, Kinoshita T, Ueda Y, Yamasaki A, Hamasaki K (2018) Moulting and growth in

1424 Wang Z, Lu Y, Greenan B, Brickman D, DeTracey B (2018) BNAM: An eddyresolving North Atlantic 1425 Ocean model to support ocean monitoring. Can Tech Rep Hydrogr Ocean Sci 327. 